\title{
Microbial Community Structures in High Rate Algae Ponds for Bioconversion of Agricultural Wastes from Livestock Industry for Feed Production
}

\author{
A. Mark Ibekwe ${ }^{1}$, Shelton E. Murinda ${ }^{2}$, Marcia A. Murry ${ }^{3}$, Gregory Schwartz ${ }^{4}$, Trygve \\ Lundquist $^{5}$
}

${ }^{1}$ US Salinity Laboratory, USDA-ARS, 450 W. Big Springs Rd., Riverside, CA 92507, USA.

${ }^{2}$ Animal and Veterinary Sciences Department, California State Polytechnic University, Pomona, CA 91768

${ }^{3}$ Biological Sciences Department, California State Polytechnic University, Pomona, CA 91768

${ }^{4}$ BioResource and Agricultural Engineering Department, College of Agriculture, California Polytechnic State University, San Luis Obispo, CA,

${ }^{5}$ Civil and Environmental Engineering Department, College of Engineering, California Polytechnic State University, San Luis Obispo, CA.

*Corresponding author:
Abasiofiok Mark Ibekwe
USDA-ARS-U. S. Salinity Laboratory
450 W. Big Springs Rd
Riverside, CA 92507.
Phone: 951-369-4828
Fax: 951-342-4964
E-mail: Mark.Ibekwe@ars.usda.gov

Key word: microbial community, high rate algae ponds, dairy lagoon effluent, algae production, Cyanobacteria, microalgae 


\section{Abstract.}

Dynamics of seasonal microbial community compositions in algae cultivation ponds are complex. However, there is very limited knowledge on bacterial communities that may play significant roles with algae in the bioconversion of manure nutrients to animal feed. In this study, water samples were collected during winter, spring, summer, and fall from the dairy lagoon effluent (DLE), high rate algae ponds (HRAP) that were fed with diluted DLE, and municipal waste water treatment plant (WWTP) effluent which was included as a comparison system for the analysis of total bacteria, Cyanobacteria, and microalgae communities using MiSeq Illumina sequencing targeting the $16 \mathrm{~S}$ V4 rDNA region. The main objective was to examine dynamics in microbial community composition in the HRAP used for the production of algal biomass. DNA was extracted from the different sample types using three commercially available DNA extraction kits; MoBio Power water extraction kit, Zymo fungi/bacterial extraction kit, and MP Biomedicals FastDNA SPIN Kit. Permutational analysis of variance (PERMANOVA) using distance matrices on each variable showed significant differences $(P=0.001)$ in beta-diversity based on sample source. Environmental variables such as hydraulic retention time (HRT; $P<$ 0.031), total N $(P<0.002)$, total inorganic N $(P<0.002)$, total $\mathrm{P}(P<0.002)$, alkalinity $(P<$ 0.002), $\mathrm{pH}(P<0.022)$, total suspended solid (TSS; $P<0.003)$, and volatile suspended solids (VSS; $P<0.002$ ) significantly affected microbial communities in DLE, HRAP, and WWTP. Of the operational taxonomic units (OTUs) identified to phyla level, the dominant classes of bacteria identified were: Cyanobacteria, Alpha-, Beta-, Gamma-, Epsilon-, and Deltaproteobacteria, Bacteroidetes, Firmicutes, and Planctomycetes. Our data suggest that microbial communities were significantly affected in HRAP by different environmental variables, and care 
must be taken in extraction procedures when evaluating specific groups of microbial communities for specific functions.

\section{Introduction:}

The need to control manure-derived nutrient pollution is straining the concentrated animal feeding operations (CAFOs) industry. California is the top milk producing state in the US and has some of the strictest manure-derived nutrient pollution regulations. These operations have little access to affordable land to use manures as a crop fertilizer or access to more land for manure application/disposal, since they produce large numbers of animals in small land areas allowing for competitive animal production. Roughly $20 \%$ of the nitrogen and $35 \%$ of the phosphorus are recovered from manure in CAFOs using land application as crop fertilizer. Substantial amounts of nutrients in the manure remain unused in the fields, and find their way into ground and surface waters (Kellogg et al., 2000). In 2-5\% of all counties in the U.S., including the agricultural regions of California, Virginia, and much of the southeast, the amount of nutrients present in the manure produced by CAFOs is greater than the entire assimilative nutrient capacity of all the cropland and pastureland available in those counties (USEPA, 2003). As a result, large amounts of manure are overapplied, exported to other locations or stored on site. The primary source of agricultural non-point source contamination in California's groundwater is the improper disposal of manure wastes by CAFOs manure (Halperin et al., 2001). Thus, there is a critical and urgent need to control manurederived greenhouse gases and nutrient pollution while reclaiming water and nutrients.

A highly productive crop is needed that will convert manure $\mathrm{N}$ and $\mathrm{P}$ into feed but in smaller land areas than traditional crops such as corn. Algae are a candidate feed with annual yields typically 
7-13 times greater than soy or corn. With beyond $40-50 \%$ protein content, algae contain fatty acids, favorable amino acid contents, pigments, and vitamins that are valuable in animal feeds, especially for adding value to milk. Microalgae have great potential both for sustainable bioremediation of wastewaters and as a feedstock. Microalgae are more efficient for $\mathrm{N}$ and $\mathrm{P}$ reclamation than higher plants, due in part, to higher rates of biomass production but also because algae lack the large stores of structural carbon (i.e., cellulose) characteristic of land plants (Kumar and Das 2012). They are photosynthetic organisms that assimilate $\mathrm{N}$ and $\mathrm{P}$ during growth. The subsequent biomass generated can be converted to high energy and feed stock after further processing. Thus, the $\mathrm{C} / \mathrm{N}$ ratio of higher plants ranges from 18-120 (by atoms) while microalgae ranges from 5-20 (Collos and Berges 2003) indicating that water reclamation and nutrient recovery can be accomplished more rapidly and in a smaller area using algae rather than terrestrial plants.

Mass-culture of algae on manure $\mathrm{N}$ and $\mathrm{P}$ is an alternative to land spreading of manure effluents, particularly in the case of CAFOs where groundwater contamination is problematic and more land for manure application is restricted. Microalgae are photosynthetic organisms with high productivity (many strains double in less than a day) that removes eutrophying nutrients from water sources. They have been used for over 50 years in municipal wastewater treatment (Oswald, 1988) and more recently for bioremediation of manure effluents (Woertz et al., 2009, Mulbry et al., 2008). Some microalgae produce lipids, rather than carbohydrates, as their primary carbon storage molecules and thus, there has been considerable interest in coupling wastewater treatment to produce feedstock for renewable fuel production. Like higher plants, microalgae produce triacyglycerides that can be readily converted to fatty acid methyl esters, a substitute for fossil-derived diesel fuel. Microalgae also have high protein content and the ability to grow in saline or wastewaters not suitable for agricultural irrigation. Of interest for both algae biofuel and algae feed is the high amounts of oil (lipid) produced, 
primarily as triglycerides. Algal neutral storage lipids are similar in structure and molecular weight (carbon chains ranging from 12-22) to the oils extracted from terrestrial plants. Microalgae can have oil contents that vary from $15-77 \%$ of the dry weight (Banerjee et al., 2002; Chisti, 2007) compared with $4 \%$ in corn. The high oil content of some algal strains is also of interest to the dairy industry as lipids are a key component in feed supplements for lactating dairy cows.

The growth of microalgae may be impeded by many contaminants in the bioreactors or in HRAP. A key hurdle in sustainable large-scale algae production, in common with terrestrial crop production, is species control. Pond performance can be negatively affected by the establishment of zooplankton grazers that can consume much of the algal biomass within a few days (Montemezzani et al., 2015). Populations of zooplankton grazers, parasitic fungi and infective bacteria and viruses are inevitable in outdoor ponds. High ammonium levels ( Schluter and Groeneweg, 1985; Lincoln et al., 1983), low nocturnal $\mathrm{pO}_{2}$ levels, large colonial forms of algae and associated microbial consortiums may effectively control some zooplanktonic herbivores (O'Brien and De Noyelles, 1972; Schluter and Groeneweg, 1981; Montemezzani et al., 2015). There are many methods for the control of zooplanktons in HRAP without detrimental effects on microalgae communities and water quality, and may include physical, chemical, biological, and enzymatic methods (Montemezzani et al., 2015). Microbial community dynamics in pond operations may provide special benefits for the investigation of population and community dynamics to determine early warning signs of a deteriorating pond that may be contaminated by zooplanktons, Cyanobacteria, or pathogens. A number of Cyanobacteria species produce potent hepatotoxins or neurotoxins that can be transferred through the food web where they may kill other life forms such as zooplankton, shellfish, fish, birds, marine mammals and humans that feed, either directly or indirectly, on them (Warrington, 2001). 
In this study four identical HRAPs were installed adjacent to the dairy waste lagoons at the 300-head dairy at California Polytechnic State University, San Luis Obispo (CPSLO), CA (Figure 1). The algae ponds are paddle wheel-mixed raceways that simulate standard 30-cm deep algae production ponds. The main objective of our study was to examine dynamics in microbial community composition in the HRAP used for the production of algal biomass. For a successful study of bacterial community dynamics in HRAP, we added a secondary objective to examine which extraction kit will produce the highest diversity of Cyanobacteria and other microalgae community in the HRAPs. We hypothesized that changes in solar radiation, temperature, hydraulic and solids residence times, and nutrients will influence bacterial, Cyanobacterial and other microalgae community compositions in the HRAPs. We used MiSeq Illumina V4 16S rDNA sequencing to examine microbial community compositions in HRAPs. MiSeq Illumina sequencing provides sufficient sequencing depth to cover the complex microbial communities (Shendure and Ji, 2008) in the pond to enable studies on the bacterial communities that may provide different functions in the ponds. For these reasons, we believe that the elucidation of bacterial and algal taxa based on deep sequencing may provide some insights into bacterial and algal communities and their interactions in HRAPs, and facilitate monitoring of presence of toxigenic cyanobacteria.

\section{Materials and methods}

\subsection{Apparatus and operation}

Four identical HRAPs were installed adjacent to the DLE at the 300-head CPSLO dairy (Fig. 1). The HRAPS are paddle wheel-mixed raceways that simulate standard 30-cm deep algae production ponds as previously described for municipal wastewater treatment research (Ward, 2011; Weissman et al., 1988). These ponds were operated as two sets of duplicates to conduct 
controlled experiments to determine parameters to be used in optimization of wastewater treatment and algae feed production. Physical parameters of the units, such as, volume and the relationship between paddle wheel RPM and channel water velocity, as well as cross sectional flow patterns that are critical for developing bio flocculating algal communities were analyzed.

The algae ponds were fed dairy flush water from the stored DLE. Data were collected from the outdoor pilot scale HRAPs under steady-state conditions (Fig. 1) during winter, spring, summer, and fall. Nutrient additions as well as fractions of nutrients from DLE were adjusted to meet the growth needs of the algae enabling development of a productivity model based on multiple variables, including: hydraulic residence time (HRT), solar radiation, water temperature, available nutrient concentration, and primary nutrient source. Nutrient adjustment was achieved by adding fertilizer in the form of water soluble Miracle Grow, 24-8-16 (N-P-K; Home Depot, San Luis Obispo, CA). Fertilizer was added as supplemental nutrients to determine if the units fed DLE were inhibited due to the dark color of the units (which promotes bacterial instead of algal growth). The $\mathrm{N}$ consisted of ammonia (3.5\%) and urea (20.5\%), while the $\mathrm{P}$ was in the phosphate form. As a function of routine dairy operation and weather, the nutrient concentrations (total N, total inorganic N, nitrate, total P) in the DLE were changing throughout the trials. Samples of the DLE were characterized to gain an understanding of the types of nutrients present. Analysis of $\mathrm{N}$ and P nutrients, solids, chemical oxygen demand (COD) and alkalinity were determined. Water quality data that were collected and sorted by season includes: total suspended solids (TSS), volatile suspended solids (VSS), total nitrogen concentration, total inorganic nitrogen concentration, total phosphorus, alkalinity, Secchi disk visibility, oxygen concentration, $\mathrm{pH}$, and temperature. The data were analyzed to determine algal productivity and nutrient uptake rates for each season at HRTs of 4 vs. 6 days. The above experiments require analyses of samples of 
influent and effluent at least once per week for the following: total and volatile suspended solids, total ammonia N, nitrate, nitrite, and alkalinity; twice per month for the following, total biochemical oxygen demand, and soluble carbonaceous biochemical oxygen demand. The four HRAPs as well as the DLE were monitored for these compounds. The data were analyzed to determine nutrient uptake rates and algal biomass productivity for each HRT and season.

\subsection{Analysis of Microbial and Cyanobacterial Community Structure in Pond Samples}

Seasonal samples (fall, winter, spring, and summer) were collected (in duplicate) from the four HRAPs and DLE at the CPSLO dairy. Samples were also collected from the San Luis Obispo city waste water treatment plant (WWTP) for DNA analysis and comparison purposes. Samples from the three sources were collected on the same day in $1 \mathrm{~L}$ plastic bottles, maintained at about $4{ }^{\circ} \mathrm{C}$, and transported to the different laboratories for further processing. DNA was extracted from these samples for analysis of total bacteria (targeting 16S rRNA-encoding genes), Cyanobacteria and microalgae using Illumina's MiSeq next generation sequencing (NGS) platform (Illumina Inc., San Diego, CA). DNA extraction was undertaken using the Power Water extraction kit (Mo Bio Laboratories, Carlsbad, CA, USA), Fungi/bacterial DNA Mini Prep kit (Zymo Research, Irving CA, USA), and FastDNA SPIN Kit (MP Biomedicals, Solon, OH, USA) for the analysis of total bacteria and Cyanobacteria. All samples were stored at $-20^{\circ} \mathrm{C}$ after further cleanup steps with DNA Clean and Concentrator (Zymo Research Corp- Irvine CA, USA). Extracted DNA $(2 \mu \mathrm{L})$ was quantified using a Nanodrop ND-2000 C spectrophotometer (Nanodrop Technologies, Wilmington DE), and run on a 1.0\% agarose gel before it was used for V4 16S Illumina MiSeq sequencing. DNA was extracted from duplicate samples (collected $30 \mathrm{~min}$ apart) and pooled for the sequencing step. 


\subsection{Illumina MiSeq sequencing of V4 16S rDNA}

Microbiota from HRAPs, WWTP, and DLE samples were profiled using Second Genome's Microbiome Signature Discovery service (San Bruno, CA, USA). Illumina sequencing across the four seasons was used to track microbial population dynamics in the three sample types. All samples were quantified via the Qubit Quant-iT dsDNA High Sensitivity Kit (Invitrogen, Life Technologies, Grand Island, NY) to ensure that they met minimum concentration and DNA mass expectations. The V4 region of the $16 \mathrm{~S}$ rRNA genes was amplified using fusion primers $515 \mathrm{~F}$ (5'-GTGCCAGCMGCCGCGGTAA-3') and 806R (5'-GGACTACVSGGGTATCTAAT-3') (Caporaso et al., 2011), and then pooled for sequencing using MiSeq (Illumina, San Diego, CA, USA).

\subsection{Statistical analysis of sequence data}

Using the software QIIME (Kuczynski et al., 2011), UCLUST (Edgar, 2010) and MOTHUR (Schloss et al., 2009), sequences were clustered into reference OTUs and assigned taxonomic classification from the Greengenes database (McDonald et al., 2012). Sequenced paired-end reads were merged, quality filtered, and dereplicated with USEARCH (Edgar, 2013). The resulting unique sequences were then clustered at 97\% similarity by UPARSE (de novo OTU clustering) and a representative consensus sequence per de novo OTU was determined (Edgar, 2013). The clustering algorithm also performs chimera filtering to discard likely chimeric OTUs. Sequences that passed quality filtering were then mapped to a set of representative consensus sequences to generate an OTU abundance table. Representative OTU sequences were assigned taxonomic classification via MOTHUR's bayesian classifier at 80\% confidence; the classifier 
was trained against the Greengenes reference database of 16S rRNA gene sequences clustered at 99\%. After the taxa were identified for inclusion in the analysis, the values used for each taxasample intersection were populated with the abundance of reads assigned to each OTU in an OTU table. A corresponding table of OTU Greengenes classification was generated. Alphadiversity (within sample diversity) metrics were calculated to estimate sample richness and Shannon diversity. Beta-diversity (sample-to-sample dissimilarity) metrics were calculated, for the inter-comparison in a pair-wise fashion, to determine dissimilarity score in a distance dissimilarity matrix. Abundance-weighted sample pair-wise differences were calculated using the Bray-Curtis dissimilarity. All analyses were generated using Second Genome R package (Vegan: R package version 2.2-1). Bray-Curtis dissimilarity was calculated using the ratio of the summed absolute differences in counts to the sum of abundances in the two samples using the Jaccard index. Hierarchical clustering maps of the samples in the form of dendrograms and principal coordinate analysis (PCoA) were used to visualize complex relationships between samples. Permutational analysis of variance (PERMANOVA) was utilized to find significant differences among discrete categorical or continuous variables based on the Monte Carlo permutation test. Univariate differential abundance of OTUs was tested using a negative binomial noise model for the over dispersion and Poisson process intrinsic to these data, as implemented in the DESeq2 package (Love et. al. 2014), and described for microbiome applications (McMurdie and Holmes 2013).

\section{Results}

\subsection{Nutrient removal in the raceway ponds}


Water quality data were collected weekly from all four algae growth reactors and sorted by season (winter, spring, summer, and fall)-Fig.2A, B and C). Total $\mathrm{N}$ and $\mathrm{P}$ uptakes from the four algae production bioreactors were monitored and the data are summarized based on seasons. The rates were calculated for the collected data points and the weekly data were averaged to determine seasonal uptake rates. $\mathrm{N}$ uptake rates were lower than expected, averaging $1.10 \mathrm{~g}$ $\mathrm{N} / \mathrm{m}^{2} /$ day during winter months. The uptake rates were significantly $(\mathrm{P}<0.002)$ lower during spring, summer and fall. $\mathrm{P}$ uptake rates averaged $0.16 \mathrm{~g} \mathrm{P} / \mathrm{m}^{2} /$ day. Generally, spring and summer rates reach about $0.2 \mathrm{~g} \mathrm{P} / \mathrm{m}^{2} /$ day but were significantly lower in fall $(\mathrm{P}<0.002)$ than in spring and summer (Fig.2A). Dissolved oxygen concentration was also monitored and recorded daily in the early afternoon along with $\mathrm{pH}$ and temperature (data not shown). The afternoon dissolved oxygen and $\mathrm{pH}$ were higher in bioreactor units 2 and 4 than in units 1 and 3 . Units 2 and 4 received a combination of DLE and fertilizer while units 1 and 3 received DLE only. The higher DO and $\mathrm{pH}$ indicate greater photosynthesis rates and higher productivity. TSS was lower in winter and fall than summer and spring. During spring and summer TSS was significantly higher $(\mathrm{P}<0.003)$ using the 6 day HRT vs. the 4 day HRT (Fig.2B). VSS was significantly higher in spring and summer $(\mathrm{P}<0.002)$ using the 6 day HRT vs. the 4 day HRT (Fig.2C).

The $\mathrm{N}$ and $\mathrm{P}$ data were analyzed to determine algal productivity and nutrient uptake rates for each season and HRT. The uptake rates were calculated from the algae productivity numbers as algae contains $10 \% \mathrm{~N}$ and $1.25 \% \mathrm{P}$. Algal productivity was determined by calculating the daily algae production from the VSS measurements (Fig.2D). VSS was significantly higher (P < 0.05) for the shorter HRT, averaging about $13 \mathrm{~g} \mathrm{VSS} / \mathrm{m}^{2} /$ day in spring, summer, and fall, and 11 $\mathrm{g} \mathrm{VSS} / \mathrm{m}^{2} /$ day in winter. These data suggest that about 140 to $210 \mathrm{~kg}$ of algae can be produced $/ 4,047 \mathrm{~m}^{2} /$ year in bioreactors operating at 4 and 6 day HRTs, respectively. This 
indicates a high potential to produce algal biomass for enhanced animal feed supplements.

\subsection{Diversity of microbial communities}

Bacterial V4 16S rRNA gene analysis was performed to characterize the microbial communities associated with the DLE, HRAPs and WWTP effluent. After processing and chimera removal, numbers of DNA sequences per sample ranged from a minimum of 90,767 to a maximum of 562,789 reads (Fig.3A). All three DNA isolation kits were able to identify and differentiate taxa abundance by sample type. However, the MP Bio kit yielded higher numbers of OTUs than Mo Bio and ZYMO kits based on rarefaction curves (Fig. 3A), whereas, the Mo Bio kit produced the highest numbers of sequence reads $(562,789)$ while MP Bio produced the lowest $(410,000)$. Except for the DLE, Shannon diversity $\left(H^{\prime}\right)$ was significantly higher $(\mathrm{P}<0.001)$ with the MP Bio kit than Mo Bio and ZYMO kits for all other test samples (Table 1). Holding the sampling depth constant for the 3 kits, MP Bio samples showed the highest number of unique OTUs in waste water samples, but lowest in HRAPs (Fig. 3B). Of the OTUs identified to taxa level, the dominant classes of bacteria identified in all samples were Cyanobacteria, Alpha-, Beta-, Gamma-, Epsilon-, and Delta-proteobacteria, Bacteroidetes, Firmicutes, and Planctomycetes. All percentages from the different OTUs are presented in Table 2.

When these samples were reanalyzed based on sources instead of extraction method Proteobacteria had the highest percent concentration followed by Firmicutes, Bacteroidetes, and Cyanobacteria (Fig. 3C). The clades that were more abundant in DLE were also abundant in HRAP. However, higher abundance was found in DLE than in HRAP and WWTP. Furthermore, we compared HRAPs, DLE, and WWTP microbial composition at the genus level. The HRAP samples had higher heterogeneity within the group than DLE samples, as the former samples occupied a bigger area in ordination space. Community composition among the three sample 
sources depended on differences in environmental parameters (i.e., nutrients, $\mathrm{pH}$, hydraulic retention times, etc.). Environmental variables such as hydraulic retention time (HRT; $P<$ $0.031)$, total $\mathrm{N}(P<0.002)$, total inorganic $\mathrm{N}(P<0.002)$, total $\mathrm{P}(P<0.002)$, alkalinity $(P<$ 0.002), $\mathrm{pH}(P<0.022)$, total suspended solid (TSS; $P<0.003)$, and volatile suspended solids (VSS; $P<0.002$ ) significantly affected microbial communities in DLE, HRAP, and WWTP. The 100 most significant OTUs were examined in HRAP and each OTU was considered significant if their corrected p-value was $\leq 0.05$, and the absolute value of their log2-fold change was $\geq 1$ (Tables S1). Similar to HRAPs comparison, the dairy pond samples had higher heterogeneity within the group, as they occupied a bigger area in ordination space. The 100 most significant different OTUs detected in DLE (Table S2) and WWTP (Table S3) are presented for comparisons. Due to the toxicity nature of Cyanobacteria to algae, a total of 418 Cyanobacteria were identified (Table S4). Further analysis of the 418 species showed that $7.65 \%$ came from DLE and these species were significantly higher in DLE than in HRAP and WWTP. On the contrary, only $4.31 \%$ and $2.63 \%$ were significantly higher in WWTP and HRAP, respectively than in DLE (Table 3). This analysis further showed that only OUT 3, 39, 2402, and 2823 were present at significant relative percent concentrations in the three sources. Five OTUs (19, 73, 185, 906, and 10098) were present in HRAP but not in the DLE, suggesting that these OTUs may have been enriched within the HRAP unit. Seasonally dominant algal species present in HRAPS were identified using microscopy and a digital camera. This predominantly identified Scenedesmus species. Other isolates identified were Scenedesmus, Chlorella, Desmodesmus and a variety of small Chlorophyta.These may likely be some of the OTUs identified by sequencing.

The relative abundances of nine major phyla isolated with the three kits are shown in Fig.4A. Relative abundance data showed that extraction technique did not influence the percent 
relative abundance of most of the nine major phyla presented in Fig.4A except for the Zymo extraction kit which produced the highest relative abundance of Cyanobacteria. At the family level, nine bacterial taxa were relatively dominant in the sample sources, with Mo Bio kit producing significant relative abundances of Oxalobacteraceae and Spingomonadaceae, while samples extracted with Zymo kit showed a higher proportional abundance of Chlamydomonadaceae, a family of microalgae (Fig. 4B), with Chlamydomonadaceae, being the most abundant taxa at the family rank, followed by Oxalobacteraceae.

\subsection{Drivers of microbial community composition in HRAPs, DLE, and WWTP effluent}

Dimensional reduction of the Bray-Curtis distance between microbiome samples using PCoA analysis showed that sample type was the main driver for the microbiome difference in the sample set. HRAPs and WWTP effluent were separated along Axis 1 in the abundance ordination analysis, which accounted for $35.4 \%$ of the variance. Furthermore, the DLE samples were separated from the rest of the samples along Axis 2, which accounted for $15.9 \%$ of the variance (Fig. 5A). PCoA analysis by taxa membership metrics only explains $10 \%$ of variance in the two highest axes combined, suggesting that taxa presence/absence is not as strong a driving force in sample differentiation as abundance metrics (data note shown). Hierarchical clustering based on Bray-Curtis distance separated the sample types into three distinctive clades (Fig.5B). PERMANOVA with Monte Carlo permutation test showed that the type of DNA isolation kit had no significant effects $(\mathrm{P}<0.268)$ on beta diversity, but samples types were major significant factors in microbial beta diversity $(\mathrm{P}<0.001)$. 


\section{Discussion}

\subsection{Pilot scale HRAPs}

Data were collected from the outdoor pilot scale HRAPs for one year to develop a predictive growth model for algal based treatment systems. Data were collected to help develop a productivity model based on multiple variables which included: hydraulic residence time (HRT), solar radiation, water temperature, available nutrient concentration, and primary nutrient source. A pH control system was set up during this period to introduce carbon dioxide into the system as needed, based on unit $\mathrm{pH}$. This $\mathrm{pH}$ control system ensured carbon limitation would not retard biomass production. As a function of dairy operation and weather, the nutrient concentrations (total nitrogen, total inorganic nitrogen, nitrate, total phosphate) in the DLE were changing throughout the trials, therefore samples of the DLE were characterized continuously to gain an understanding of the types of nutrients present in the HRAPs . As a result DLE effluent was diluted to 3-7\% of the daily refill volume depending on the season to promote green water or algae-based treatment system as opposed to brown water or bacteria-based treatment system. Water quality data are presented in Figure 2 and these include TSS, VSS, total nitrogen concentration, total phosphorus, alkalinity, oxygen concentration, $\mathrm{pH}$, and temperature. The data were analyzed to determine algal productivity and nutrient uptake rates for each season at HRTs of 4 and 6 days (Fig. 2A-D). Algal productivity values ranged 6.5-13.9 g/m²/day, whereas, nutrient

uptake values ranged 0.8-1.4 $\mathrm{g} \mathrm{N} / \mathrm{m}^{2} /$ day and $0.08-0.17 \mathrm{~g} \mathrm{P} / \mathrm{m}^{2} /$ day and were all higher at HRTs of 4 days in all seasons. 
Raceway ponds are probably the most common technology used for treatment of municipal and agricultural wastewaters in the US, with over 7,000 publicly-owned treatment pond and lagoon systems (USEPA, 2008). However, nutrient removal is an increasingly common regulatory requirement, and conventional ponds are not well suited for nitrogen and phosphorus removal. Newer pond technologies (e.g., paddle wheel-mixed raceway ponds (HRAPs), Fig. 1, and newer variants of aerated lagoons) have advanced the reliability and effectiveness. In this study the removal rate of $\mathrm{N}$ was between 75 and $85 \%$ from DLE total $\mathrm{N}$ load to the HRAPs. The removal rate for $\mathrm{N}$ was better than the removal rate for $\mathrm{P}$, but similar to many studies in the literature (Taziki et al., 2015). At dairies and swine farms, for example, algae production/wastewater treatment systems can be used to remove $\mathrm{N}, \mathrm{P}$, and dissolved organic matter from barn flush water, while producing high protein biomass (Whitten et al., 2015). Such treatment is already commercially available for municipal wastewater treatment in the US and for dairy in New Zealand, albeit with only a few installations and without algae feed production.

\subsection{Microbial communities in the HRAPs}

The dominant phyla from our study showed Proteobacteria with the highest relative abundance (0.10.8) for all the phyla identified. This was followed by Bacteroidetes, Firmicutes, Actinobacteria, Verrucomicrobia, and Cyanobacteria. All classifications were based on the Greengenes reference database of 16S rRNA gene sequences clustered at 99. DNA samples isolated from the ZYMO kit had a higher proportional abundance of Chlamydomonadaceae, a family of green microalgae. The presence of Chlamydomonadaceae, which belongs to the Chlorophyta phylum, may support $\mathrm{H}_{2}$ production by dark fermentation under anaerobic conditions (Yang et al., 2013). Cyanobacteria are important components of the HRAPs (Table S1-S3) providing photosynthetic oxygen production indicating that Cyanobacteria and other microalgae can contribute to wastewater nutrient remediation. 
The other dominant photoautotrophs identified to genus level included the Leptolyngbya. This photoautotrophs was significantly more abundant $(\mathrm{P}<0.0031)$ in HRAPs than in DLE. This genus was only identified using the MP Bio extraction kit, suggesting the possible role of extraction techniques in bacterial community composition analysis. It should be noted that algal reference sequences are not typically as well represented as bacteria in 16S rRNA sequence databases, and that even more careful targeting (e.g., 18S rRNA), could lead to large proportions of unidentified sequences (Xiao et al., 2015).

Bacterial family sequence numbers were adjusted to the median sequence number for the three sample sources and differences at the family levels are shown in Fig. 5B. One of the species identified was Polynucleobacter cosmopolitanus of the Oxalobacteraceae family which possess a large photosynthetic gene cluster containing all key genes of anoxygenic photosynthesis (Haln et al., 2010; Hahn et al., 2012). Among the Rhodobacteraceae (Alphaproteobacteria) and the genus Rhodobacter was detected in all the sample sources and these genera include species which possess an extensive range of metabolic capabilities. Rhodobacter sphaeroides is the most-studied photosynthetic organism in terms of the structural and functional light reactions, and the metabolic capabilities of each species generate great interest within the research community, especially with regards to renewable energy sources. Rhodobacter are found in freshwater or marine environments (Xiao et al., 2015). Bacterial taxa with potential negative effects on algal growth, e.g. Pseudomonas and Bdellovibrionaceae (Carney et al., 2014), were identified in all of our samples. Notable Xanthomonadaceae species identified in ponds included the common aquatic bacterium Aquimonas genus with some species like Aquimonas voraii, which has extracellular phosphatase activity (von Tigerstrom et al., 1987) that could improve phosphorus availability for algae. 
As shown in Table 2 and in Table S1-S3, the relative abundances of the species detected was more dependent on the samples sources rather than on the choice of DNA extraction procedure (Fouhy et al., 2016). Notable differences occurred based on phyla, namely the Cyanobacteria cells had a higher relative abundance using the ZYMO procedure compared to the Mo Bio or MP Bio procedures. These results suggest subtle differences occur in sequencing data as a result of the DNA extraction protocol used. Extraction methods had a lesser effect on overall composition, since no significant differences $(\mathrm{P}<0.249)$ were identified based on extraction procedure. DNA extraction procedure may have significant impact on sequencing results (McOrist et al., 2002). Several studies have previously shown the effects of using different commercial kits for DNA extraction from fecal samples on sequencing outcomes (Nechvatal et al., 2008; Kennedy et al., 2014; Walker et al., 2015). Our approach was to focus specifically on three extraction methods commonly used in microbial ecology studies to establish if they produce the same level of relative abundances of major bacterial families that may coexist with algae in an algal production pond. The three extraction procedures yielded DNA that gave comparable results with respect to phylogeny, but with some minor differences in taxa diversity at the genus level Table S1-S3).

\section{Conclusion}

The use of next generation sequencing has significantly enhanced our understanding of microbial community dynamics in HRAPs used for the bioconversion of animal waste to nutrients. However, for success in this kind of study, the best DNA extraction procedure must be followed for good quality DNA. As a result many OTUs were identified using the fungi/bacterial DNA Mini Prep kit from Zymo 
Research which were similar to Scenedesmus, Chlorella, Desmodesmus and a variety of small Chlorophyta which were also identified by microscopy. These OTUs or species identified microscopically may facilitated the conversion of DLE N and P to algal biomass thus facilitating the removal of $\mathrm{N}$ and $\mathrm{P}$ from animal waste and improving the quality of the resultant effluent water. The technology provides many advantages to society as a whole by providing better quality water with less residual $\mathrm{N}$ and $\mathrm{P}$ that may contaminate ground and surface water, building algal biomass that may be used as an animal feed, alternative energy source, or for other products.

ACKNOWLEDGEMENTS - This research was supported by the USDA-AFRI-NIFA Award \# 2013-67019-21374. Mention of trade names or commercial products in this publication is solely for the purpose of providing specific information and does not imply recommendation or endorsement by the U.S. Department of Agriculture. The U.S. Department of Agriculture (USDA) prohibits discrimination in all its programs and activities on the basis of race, color, national origin, age, disability, and where applicable, sex, marital status, familial status, parental status, religion, sexual orientation, genetic information, political beliefs, reprisal, or because all or part of an individual's income is derived from any public assistance program. 


\section{References}

Banerjee, A., Sharma, R., Chisti Y., and U. C. Banerjee. 2002. Botryococcus braunii: A renewable source of hydrocarbons and other chemicals. Crit Rev Biotech. 22-245-279.

Caporaso, J.G., Lauber, C., Walters, W.A., Berg-Lyons, D., Lozupone, C.A., Turnbaugh, P.J et al. 2011. Global patterns of 16S rRNA diversity at a depth of millions of sequences per sample. Proc. Natl. Acad. Sci. USA. 15, 4516-4522.

Carney, L.T., Reinsch, S.S., Lane, P.D., Solberg, O.D., Jansen, L.S., Williams, K.P., Trent, J.D., Lane, T.W., 2014. Microbiome analysis of a microalgal mass culture growing in municipal wastewater in a prototype OMEGA photobioreactor. Algal Res. 4, 52-61

Chisti, Y. 2007. Biodiesel from microalgae. Biotech Adv. 25, 294-306.

Collos, Y., Berges, J.A., 2003. Nitrogen metabolism in phytoplankton. In C.M. Duarte (Ed. Encyclopedia of life support systems. EOLSS publishers. (UNESCO) HTTP://WWW.EOLSS.net/PDF.

Edgar, R.C., 2010. Search and clustering orders of magnitude faster than BLAST. Bioinf. 26, $2460-2461$.

Edgar, R.C., 2013. UPARSE: highly accurate OTU sequences from microbial amplicon reads. Nat. Methods 10: 996-998.

Fouhy, F., Clooney, A.G., Stanton, C., Claesson, M.J., Cotter, P.D., 2016. 16S rRNA gene sequencing of mock microbial populations- impact of DNA extraction method, primer choice and sequencing platform. BMC Microbiology.16:123 DOI: 10.1186/s12866-0160738-Z

Hahn, M.W., Lang, E., Brandt, U., Lu, H., Wu, Q.L., Stackebrandt, E., 2010. Polynucleobacter 
cosmopolitanus sp. nov., free-living planktonic bacteria inhabiting freshwater lakes and rivers. International Journal of Systematic and Evolutionary Microbiology (2010), 60, $166-173$.

Hahn, M.W., Scheuerl, T., Jezberova, J., Koll, U., Jezbera, J., et al. 2012. The passive yet successful way of planktonic life: genomic and experimental analysis of the ecology of a free-living polynucleobacter population. PLoS ONE 7(3): e32772. doi:10.1371/journal.pone.0032772.

Kellogg, R.L., Lander, C.H., Moffitt, D.C., Gollehon. N., 2000. Manure nutrients relative to the capacity of cropland and pastureland to assimilate nutrients-spatial and temporal trends for the United States. GSA Publ. nsp00-0579. USDA-NRCS-ERS, Riverside, CA.

Kennedy, N.A., Walker, A.W., Berry, S.H, Duncan, S.H., Farquarson, F.M., Louis, P., Thomson, J.M., Ahmad, T., Satsangi, J., Flint, H.J., 2014. The impact of different DNA extraction kits and laboratories upon the assessment of human gut microbiota composition by $16 \mathrm{~s}$ rRNA gene sequencing. PLoS One. 9, e88982.

Kuczynski, J., Stombaugh, J., Walters, W.A., González, A., Caporaso, J.G., Knight, R., 2011. Using QIIME to analyze 16S rRNA gene sequences from microbial communities. Curr Protoc. Microbiol; Chapter 10:Unit 10.7. doi: 10.1002/0471250953.bi1007s36.

Kumar, K., Das D., 2012. Growth characteristics of Chlorella sorokiniana in airlift and bubble column photobioreactors. Bioresour Technol.116, 307-313.

Lincoln, E.P., Hall, T.W., Koopman, B., 1983. Zooplankton control in mass algal cultures. Aquaculture. 32, 331-337.

Love, M. I., Huber, W., Anders, S. 2014. Moderated estimation of fold change and dispersion for RNA-Seq data with DESeq2. bioRxiv. doi:10.1101/002832 
McDonald, D., Price, M.N., Goodrich, J., Nawrocki, E.P., DeSantis, T.Z., Probst, A., Andersen, GL., Knight, R., Hugenholtz, P., 2012. An improved Greengenes taxonomy with explicit ranks for ecological and evolutionary analyses of bacteria and archaea. ISME J. 6, 610-618.

McMurdie, P. J., Holmes, S. 2013. Phyloseq: an R package for reproducible interactive analysis and graphics of microbiome census data. PLoS ONE. 8. e61217.

McOrist AL, Jackson M, Bird AR.2002. A comparison of five methods for extraction of bacterial DNA from human faecal samples. J Microbiol Methods. 50, 131-9.

Montemezzani, V, I., Duggan, C., Hogg, I.D., Craggs, R.J., 2015. A review of potential methods for zooplankton control in wastewater treatment high rate algal ponds and algal production raceways. Algal Res. 11, 211-226.

Mulbry, W., Kondrad, S., Pizarro, C., Kebede-Westhead, E., 2008. Treatment of dairy manure effluent using freshwater algae: Algal productivity and recovery of manure nutrients using pilot-scale algal turf scrubbers. Bioresour. Technol. 99, 8137-8142.

Nechvatal, J.M., Ram, J.L., Basson, M.D., Namprachan, P., Niec, S.R., Badsha, K.Z., Matherly, L.H., Majumdar, A.P., Kato, I., 2008. Fecal collection, ambient preservation, and DNA extraction for PCR amplification of bacterial and human markers from human feces. $\mathrm{J}$ Microbiol Methods. 72, 124-32.

O’Brien, W.J., De Noyelles, F., 1972. Photosynthetically elevated $\mathrm{pH}$ as a factor in zooplankton mortality in nutrient enriched ponds. Ecology. 53, 605-614.

Oswald, W.J., 1988. Terrestrial approaches to integration of waste treatment. Waste Management Research. 9, 477-484.

Schloss, P.D., Westcott, S.L., Ryabin, T., Hall, J.R., Hartmann, M., Hollister, E.B et al. 2009. 
Introducing Mothur: open-source, platform-independent, community-supported software for describing and comparing microbial communities. Appl. Environ. Microbiol. 75, $7537-7541$.

Schluter, M., Groeneweg, J., 1985. The inhibition by ammonia of population growth of the rotifer, Brancionus rebens, in continuous culture. Aquaculture. 46, 215-220.

Schluter, M., Groeneweg, J., 1981. Mass production of freshwater rotifers on liquid wastes. I. The influence of some environmental factors on population growth of Brachionus rubens Ehrenberg 1838. Aquaculture 25, 17-24.

Shendure, J., Ji, H., 2008. Next-generation DNA sequencing. Nat Biotechnol 26, 11351145.

Taziki, M., Ahmadzadeh, H., Murry, M.A., Lyon, S.R,. 2015. Nitrate and Nitrite removal from wastewater using algae. Current Biotech. 4, 426-440.

USEPA. 2003. National pollutant discharge elimination system permit regulation and effluent limitation guidelines and standards for concentrated animal feeding operations (CAFOs). Fed. Regist. 69(29):7176-7274.

US-EPA. 2008. An evaluation of a covered anaerobic lagoon for flushed dairy cattle manure stabilization and biogas production. Washington, D.C.: United States Environmental Protection Agency.

von Tigerstrom, R.G., Stelmaschuk, S., 1987. Comparison of the phosphatases of Lysobacter enzymogenes with those of related bacteria. J. Gen. Microbiol.133, 3121-3127

Walker, A.W., Martin, J.C., Scott, P., Parkhill, J., Flint, H.J, Scott, K.P., 2015. 16S rRNA genebased profiling of the human infant gut microbiota is strongly influenced by sample processing and PCR primer choice. Microbiome.3, 1-11. 
Ward, P.E., 2011. Bioflocculation and CO2 Supplementation in Wastewater Treatment by Algal High-Rate Ponds, MS thesis, Civil and Environmental Engineering Department, California Polytechnic State University, San Luis Obispo.

Warrington, P., 2001. Aquatic pathogens - cyanophytes - the blue-green algae. Available Online: http://www.elp.gov.bc.ca/wat/wq/reference/toxicalgae.html.

Weissman, J.C., Goebel, R.P., Benemann, J.R., 1988. Photobiorector design: comparison of open ponds and tubular reactors. Bioeng Biotech. 31, 336-344.

Whitten, R., Mevel, A.L., Pidou, M., Ometto, F., Villa, R., Jefferson, B., 2015. Influence of microalgal $\mathrm{N}$ and $\mathrm{P}$ composition on wastewater nutrient remediation. Water Res. 91, $371-378$.

Woertz, I.C., T.J. Lundquist, A.S. Feffer, Y.M. Nelson. 2009. Lipid productivity of algae grown on dairy and municipal wastewaters for biofuel feedstock. Journal of Environmental Engineering, American Society of Civil Engineers, Vol. 135, Issue 11, pp. 1115-1122.

Xiao, L., Young, E.B., Grothjan, J.J., Lyon, S, Zhang, Z, He, Z., 2015. Wastewater treatment and microbial communities in an integrated photo-bioelectrochemical system affected by different wastewater algal inocula. Algal Research 12, 446-454

Yang, S., Guarnieri, M.T., Smolinski, S., Ghirardi, M., Pienkos, P.T., 2013. De novo transcriptomic analysis of hydrogen production in the green alga Chlamydomonas moewusii through RNA-Seq, Biotechnol. Biofuels. 6, 1-17. 
Table 1. Shannon diversity indices of samples based on DNA extraction method

\begin{tabular}{lrrr}
\hline Sample source & MO BIO & ZYMO & MP BIO \\
\hline wetland trough-1 & 2.922931 & 1.807525 & 4.250287 \\
wetland trough-2 & 3.034928 & 3.428931 & 4.673853 \\
wetland trough-3 & 3.025278 & 2.850793 & 3.424096 \\
wetland trough-4 & 2.825826 & 3.318973 & 4.773748 \\
waste water treatment plant & 1.612938 & 2.656298 & 5.399947 \\
waste water treatment plant & 1.706715 & 2.631 & 5.324516 \\
waste water treatment plant & 1.731622 & 2.30066 & 3.402613 \\
waste water treatment plant & 2.332175 & 3.029716 & 4.392655 \\
DLE effluent & 4.430778 & 5.502392 & 4.350843 \\
\hline
\end{tabular}

Replace "wetland trough" with, e.g., DLE-fed algae production ponds 
Table 2. Detection of significantly different OTUs from each DNA extraction kit

\begin{tabular}{|c|c|c|c|}
\hline \multirow[t]{2}{*}{ Phylum } & \multicolumn{3}{|c|}{ Extraction Kit (\%) } \\
\hline & MP & MoBio & Zymo \\
\hline Cyanobacteria & 3.78 & 2.5 & 2.5 \\
\hline Proteobacteria & 38.2 & 40.9 & 28.7 \\
\hline ---Beta & 6.4 & 9.5 & 4.6 \\
\hline ---Alpha & 12.6 & 16.3 & 11.7 \\
\hline ---Gamma & 7.6 & 9.3 & 5.8 \\
\hline ---Epsilon & 1.01 & 2.7 & 1.5 \\
\hline ---Delta & 8.4 & 2.5 & 4.4 \\
\hline Actinobacteria & 3.7 & 4.9 & 4.9 \\
\hline Bacteroidetes & 15.83 & 20.1 & 18.9 \\
\hline Verrucomicrobia & 7.8 & 8.8 & 8.3 \\
\hline Chloroflexi & 1.32 & 1.6 & 2.5 \\
\hline Firmicutes & 7.76 & 4.5 & 9.3 \\
\hline Tenericutes & 0.3 & 0.6 & 1.1 \\
\hline$S R 1$ & 0.6 & 0 & 0 \\
\hline Acidobacteria & 1.7 & 0.2 & 0 \\
\hline Chlorobi & 0.7 & 0.6 & 0.4 \\
\hline Planctomycetes & 5.82 & 1.8 & 3.7 \\
\hline$O D 1$ & 2.65 & 2.2 & 5.2 \\
\hline Fibrobacteres & 0.03 & 0 & 0 \\
\hline Gemmatimonadetes & 0.1 & 0.2 & 0.4 \\
\hline Chlamydiae & 0.1 & 0.2 & 0.1 \\
\hline Spirochaetes & 0.8 & 0.4 & 1.1 \\
\hline TM7 & 0.7 & 0.2 & 0.2 \\
\hline GNO2 & 0.1 & 0.6 & 0.7 \\
\hline Caldithrix & 0.1 & 0.2 & 0.1 \\
\hline Thermi & 0.1 & 0 & 0 \\
\hline NKB19 & 0.3 & 0 & 0.2 \\
\hline Armatimonadetes & 0.1 & 0 & 0 \\
\hline TM6 & 0.1 & 0 & 0.1 \\
\hline Fusobacteria & 0.4 & 6 & 0.5 \\
\hline$B R C 1$ & 1.2 & 0 & 0 \\
\hline OP3 & 0.3 & 2 & 1.6 \\
\hline$W P S-2$ & 0.3 & 0 & 0 \\
\hline$L D 1$ & 0.1 & 0.2 & 0.1 \\
\hline Elusimicrobia & 0.1 & 0.2 & 0 \\
\hline$W W E 1$ & 0 & 1.1 & 0.8 \\
\hline Lentisphaerae & 0 & 0.6 & 1.5 \\
\hline
\end{tabular}


Table 3. Cyanobacteria with percent significant differences between sample sources based on greengenes analysis

\begin{tabular}{|c|c|c|c|c|c|c|c|}
\hline OTU & Order & Family & Genus & Species & DLE-p value & $\begin{array}{l}\text { HRAP-p } \\
\text { value }\end{array}$ & WWTP-P value \\
\hline 3 & Chlorophyta & Chlamydomonadaceae & unclassified & unclassified & 0.000629 & $1.26 \mathrm{E}-15$ & $5.12 \mathrm{E}-14$ \\
\hline 19 & Chlorophyta & Chlamydomonadaceae & 94otu30054 & 97 otu5870 & & $1.12 \mathrm{E}-07$ & $2.85 \mathrm{E}-06$ \\
\hline 23 & Chlorophyta & 91 otu763 & 94otu34503 & 97 otu72584 & 0.004926 & & \\
\hline 39 & Chlorophyta & 91 otu4387 & unclassified & unclassified & $1.36 \mathrm{E}-06$ & 2.92E-07 & $2.85 \mathrm{E}-06$ \\
\hline 73 & Stramenopiles & 91 otu4345 & 94otu10147 & 97 otu13102 & & $3.50 \mathrm{E}-07$ & \\
\hline 185 & Chlorophyta & Chlamydomonadaceae & 94otu41005 & 97otu92736 & & 0.0023327 & 3.13E-06 \\
\hline 292 & Stramenopiles & 91otu4445 & 94otu10273 & unclassified & 0.0003755 & & \\
\hline 369 & Chroococcales & Cyanobacteriaceae & Cyanobacterium & 97 otu65507 & $5.36 \mathrm{E}-06$ & & \\
\hline 490 & Stramenopiles & 91 otu672 & 94otu29984 & 97 otu33082 & $6.87 \mathrm{E}-07$ & & \\
\hline 906 & Stramenopiles & 91 otu5457 & 94otu17156 & unclassified & & 0.0114097 & \\
\hline 946 & 85otu 1728 & 91 otu8766 & 94otu4415 & 97 otu5105 & 4.52E-06 & & \\
\hline 1312 & Stramenopiles & 91 otu4345 & unclassified & unclassified & $1.38 \mathrm{E}-05$ & & \\
\hline 1346 & 85 otu 754 & 91 otu6314 & unclassified & unclassified & 0.000277 & & \\
\hline 1372 & Streptophyta & 91 otu8468 & 94 otu16468 & 97 otu36443 & & & 0.0002054 \\
\hline 1631 & Chlorophyta & 91 otu4387 & unclassified & unclassified & 0.006901 & & \\
\hline 1725 & Chlorophyta & Chlamydomonadaceae & 94otu32417 & 97 otu 83273 & 0.0008228 & & \\
\hline 1726 & 85 otu 1728 & 91 otu12004 & 94otu23100 & unclassified & 0.0001622 & & \\
\hline 2402 & Chlorophyta & Chlamydomonadaceae & unclassified & unclassified & 0.0193302 & 0.0116155 & 0.0006197 \\
\hline 2504 & $\begin{array}{l}\text { Pseudanabaena } \\
\text { les }\end{array}$ & Pseudanabaenaceae & Leptolyngbya & 97 otu90470 & 0.0030998 & & \\
\hline 2518 & YS2 & 91otu5915 & 94otu16622 & 97otu5543 & & & 0.0086599 \\
\hline 2662 & Stramenopiles & unclassified & unclassified & unclassified & 0.0002578 & & \\
\hline 2692 & Chlorophyta & Chlamydomonadaceae & unclassified & unclassified & $3.16 \mathrm{E}-05$ & & \\
\hline 2823 & Stramenopiles & 91 otu4345 & 94otu12325 & unclassified & $5.16 \mathrm{E}-06$ & 0.0004138 & $6.48 \mathrm{E}-11$ \\
\hline 2839 & unclassified & unclassified & unclassified & unclassified & 0.0002829 & & \\
\hline 2908 & Chlorophyta & Trebouxiophyceae & 94otu 2543 & 97 otu29136 & & & 0.0013869 \\
\hline 3047 & YS2 & unclassified & unclassified & unclassified & 0.0052925 & & \\
\hline 3265 & Chlorophyta & Chlamydomonadaceae & unclassified & unclassified & & & 0.0021237 \\
\hline 3584 & unclassified & unclassified & unclassified & unclassified & & & 0.0129087 \\
\hline 3869 & $\begin{array}{l}\text { Synechococcale } \\
s\end{array}$ & Acaryochloridaceae & 94otu14616 & 97otu53199 & 0.0110053 & & \\
\hline 3923 & Chroococcales & Xenococcaceae & unclassified & unclassified & 0.0014368 & & 0.0069497 \\
\hline 4489 & Oscillatoriales & Phormidiaceae & unclassified & unclassified & 0.0051075 & & \\
\hline 5032 & Chlorophyta & 91 otu763 & 94otu28051 & 97 otu78782 & 0.0120289 & & \\
\hline 5654 & Stramenopiles & unclassified & unclassified & unclassified & & & 0.0110093 \\
\hline 8609 & Chlorophyta & Chlamydomonadaceae & unclassified & unclassified & & & 0.0186376 \\
\hline 10098 & Stramenopiles & 91 otu4345 & unclassified & unclassified & & $3.18 \mathrm{E}-07$ & \\
\hline 10922 & Chlorophyta & Chlamydomonadaceae & 94otu30054 & 97 otu5870 & 0.0025111 & & \\
\hline 11356 & Chlorophyta & 91 otu4387 & unclassified & unclassified & & & 0.0026257 \\
\hline 11670 & Chlorophyta & Chlamydomonadaceae & 94otu41005 & 97otu92736 & 0.0067226 & & \\
\hline 13148 & Chlorophyta & Chlamydomonadaceae & 94otu30054 & 97 otu5870 & & & 0.0018061 \\
\hline
\end{tabular}




\begin{tabular}{|c|c|c|c|c|c|c|}
\hline 13175 & Stramenopiles & 91otu4345 & unclassified & unclassified & 0.0005337 & \\
\hline 13399 & YS2 & 91otu5915 & 94otu16622 & 97 otu5543 & & 0.0084372 \\
\hline 14374 & 85 otu 1728 & 91 otu8766 & unclassified & unclassified & 0.0011139 & \\
\hline 14858 & Chlorophyta & Chlamydomonadaceae & unclassified & unclassified & & $3.50 \mathrm{E}-06$ \\
\hline 15732 & Stramenopiles & 91 otu4345 & 94otu10147 & unclassified & 0.0160404 & \\
\hline 19265 & SM1D11 & 91 otu 7744 & 94otu9796 & 97otu76577 & 7.30E-06 & \\
\hline percent & & & & & 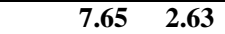 & 4.31 \\
\hline
\end{tabular}

\section{FIGURE LEGEND}

Fig. 1. Four outdoor HRAPs for algae cultivation used to monitore seasonal nutrient uptake rates, determine changes in microbial community, identified dominant algal species present, initiated bioflocculation selection, and for total biomass production. This was set up adjacent to the dairy waste lagoons at the 300-head dairy at California Polytechnic State University, San Luis Obispo (CPSLO), CA.

Fig. 2. Water quality data collected weekly from HRAPs growth reactors and sorted by season. (A) Total N and P uptakes from HRAPs production bioreactors monitored weekly. (B) TSS for 6 day vs. 4 day HRT. (C) VSS using the 6 day HRT vs. the 4 day HRT.

Fig. 3. Numbers of DNA sequences and diversity indices per sample type. (A) Rarefaction curves. Average number of OTUs detected versus sequencing library size. Sample names are annotated at the end (right) of each curve. A curve approaching a horizontal slope is nearly saturated, with few new OTUs undiscovered. A curve with a steep slope remaining in the plot has not been sequenced to saturation, and a substantial quantity of additional OTUs are expected upon further sequencing. (B) Microbiome alpha-diversity estimates for each sample Shannon diversity indices. (C) Phylogenetic tree at the Order level. The height of each bar indicates the number of samples containing that particular Order. The most abundant Phylum-level clades are colored with the remainders in light gray.

Fig.4. Composition of bacteria at the phylum and family levels. (A) Relative abundance of each phylum per sample (B) Most abundant nine groups at the taxonomic level of family.

Fig.5. Ordination using abundance. (A) Dimensional reduction of the Bray-Curtis distance between microbiome samples, using the PCoA ordination method. (B) Hierarchical clustering; ward clustering, Bray-Curtis distance.

Fig. 6. Graphic Summary of feature (OTU) selection.

(A) Mo Bio kit: Graphic Summary of Feature (OTU) Selection. B) MP BIO: graphic summary of feature (OTU) selection. (C) ZYMO: Graphic summary of feature (OTU) selection. 


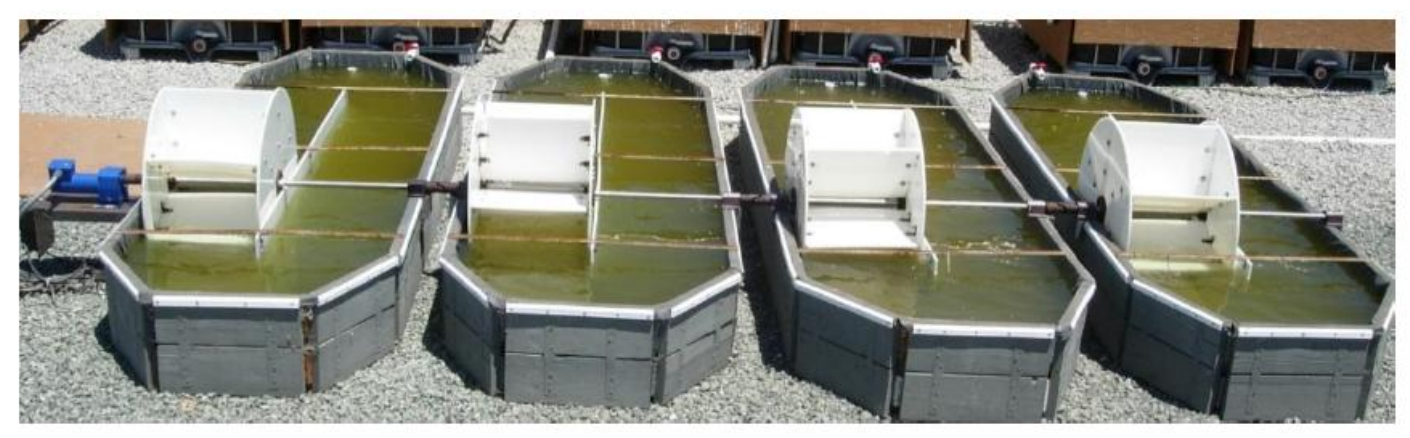

Fig. 1 


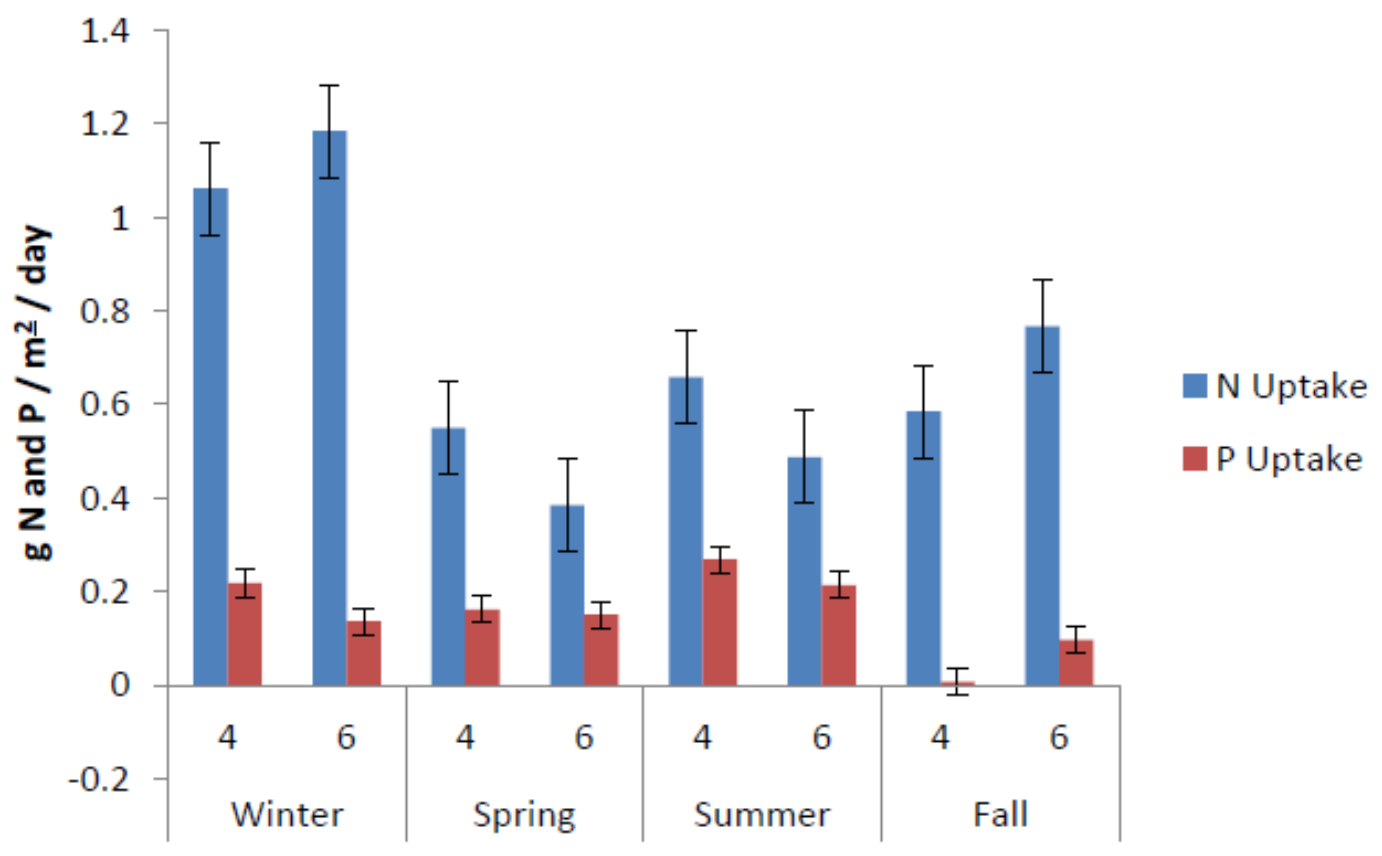

Fig. 2A 


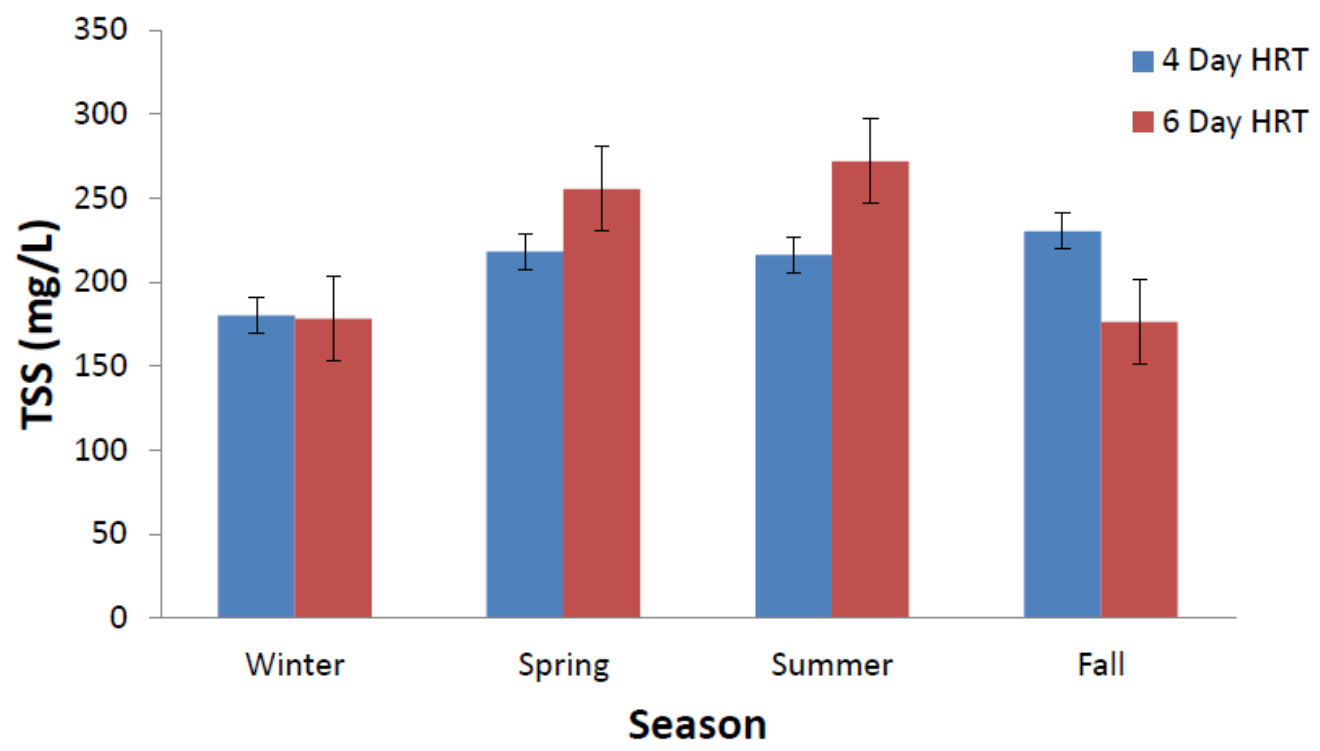

Fig. 2B 


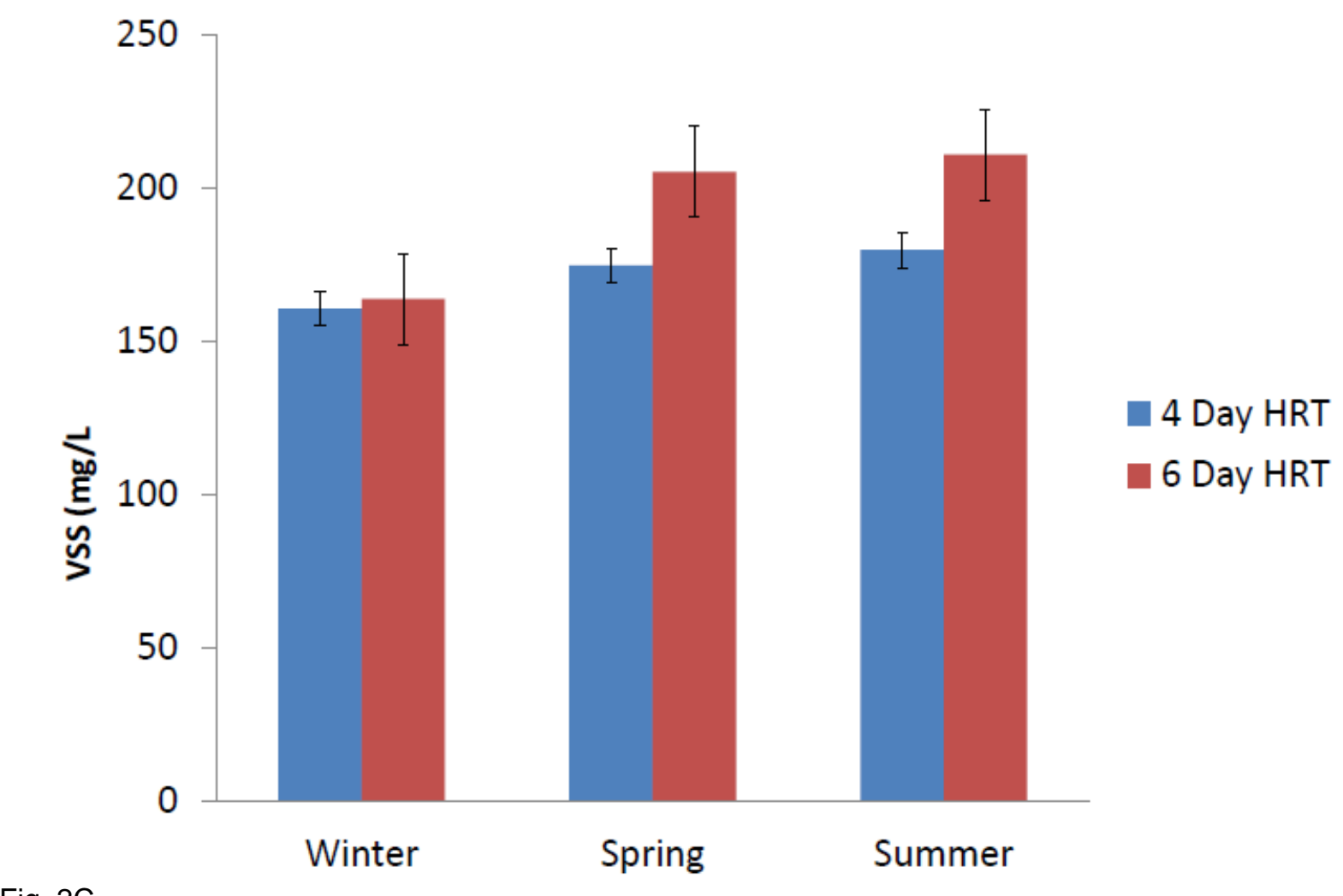

Fig. $2 \mathrm{C}$ 


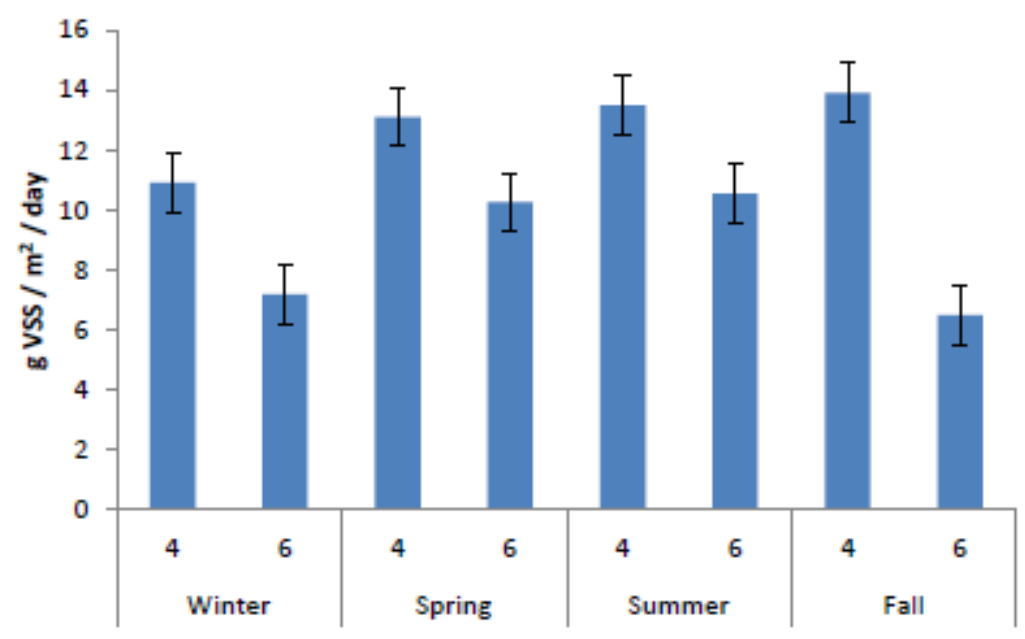

Fig. 2D 


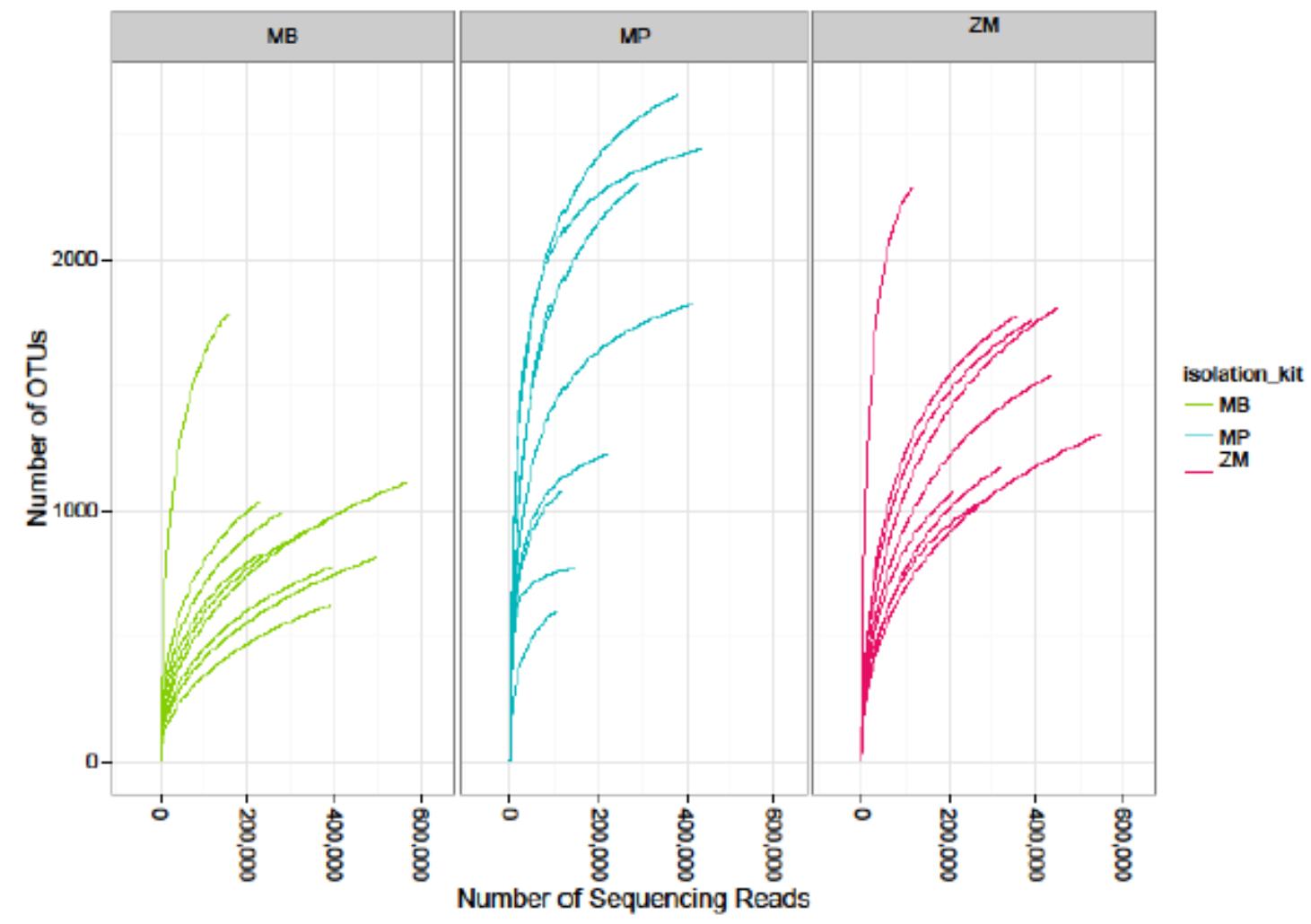

Fig. 3A 


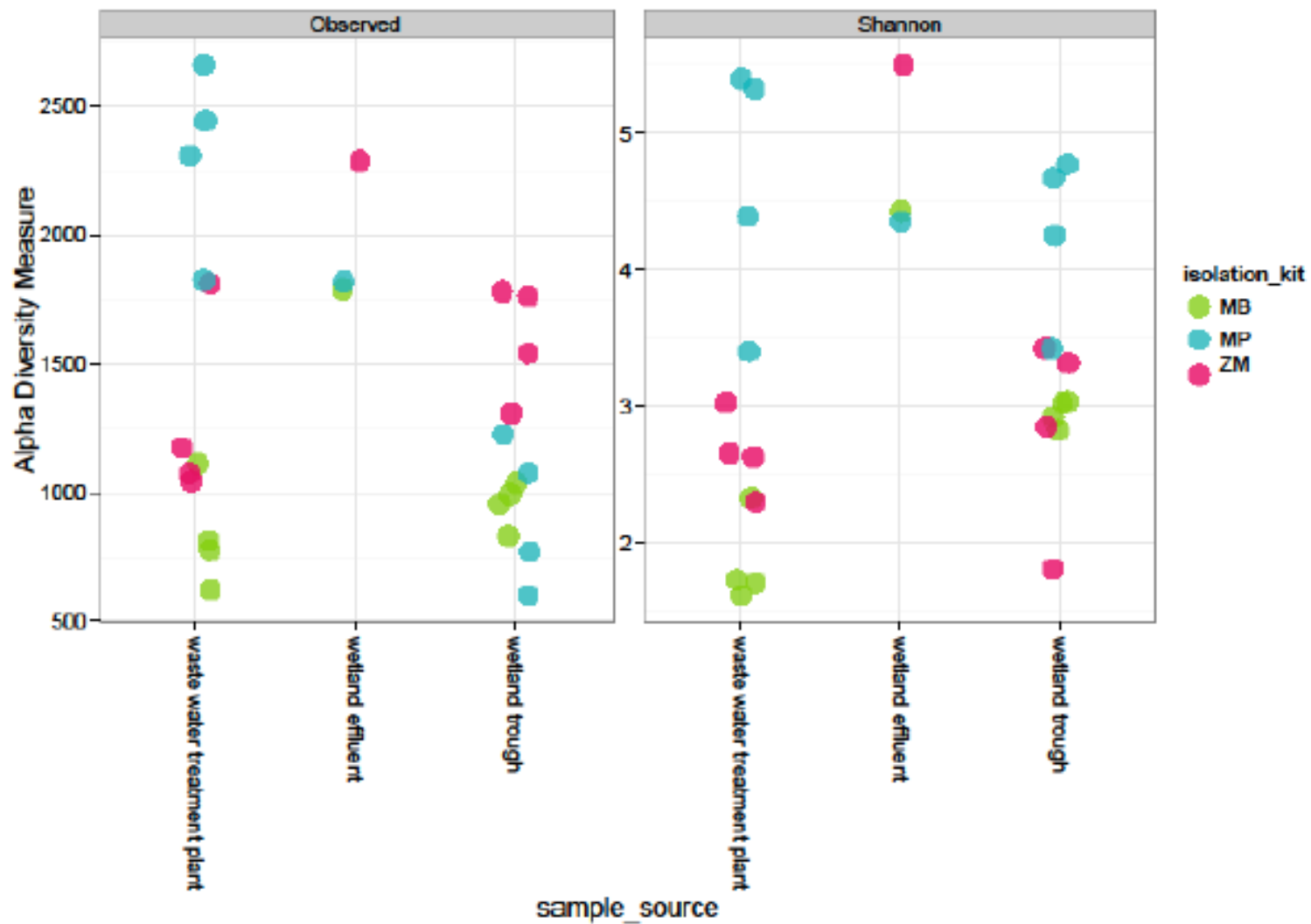

Fig. 3B 


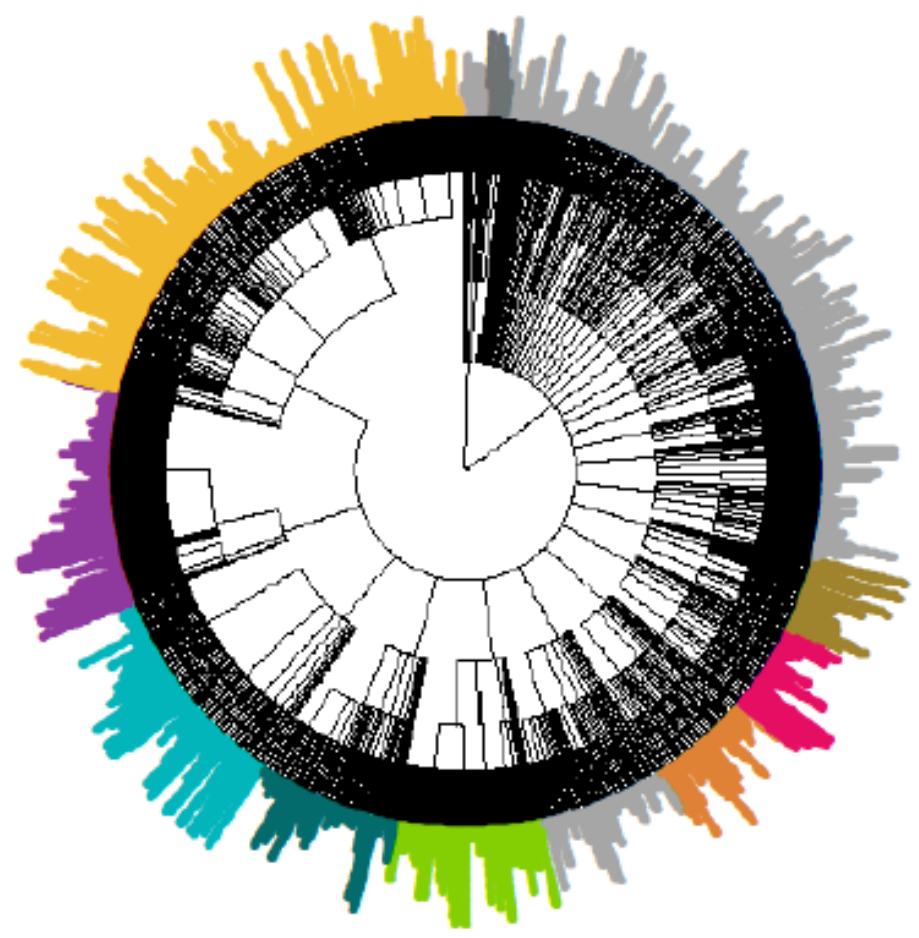

Phylum

- P_Actinobacteria

- P_Bacteroidetes

- P_Cyanobacterla

- P_Euryarchaeota

- D_Firmicutes

- P_OD1

- p_Planctomycetes

- P_Protechacteria

- P_Vertucomicrobia

Fig. 3C 


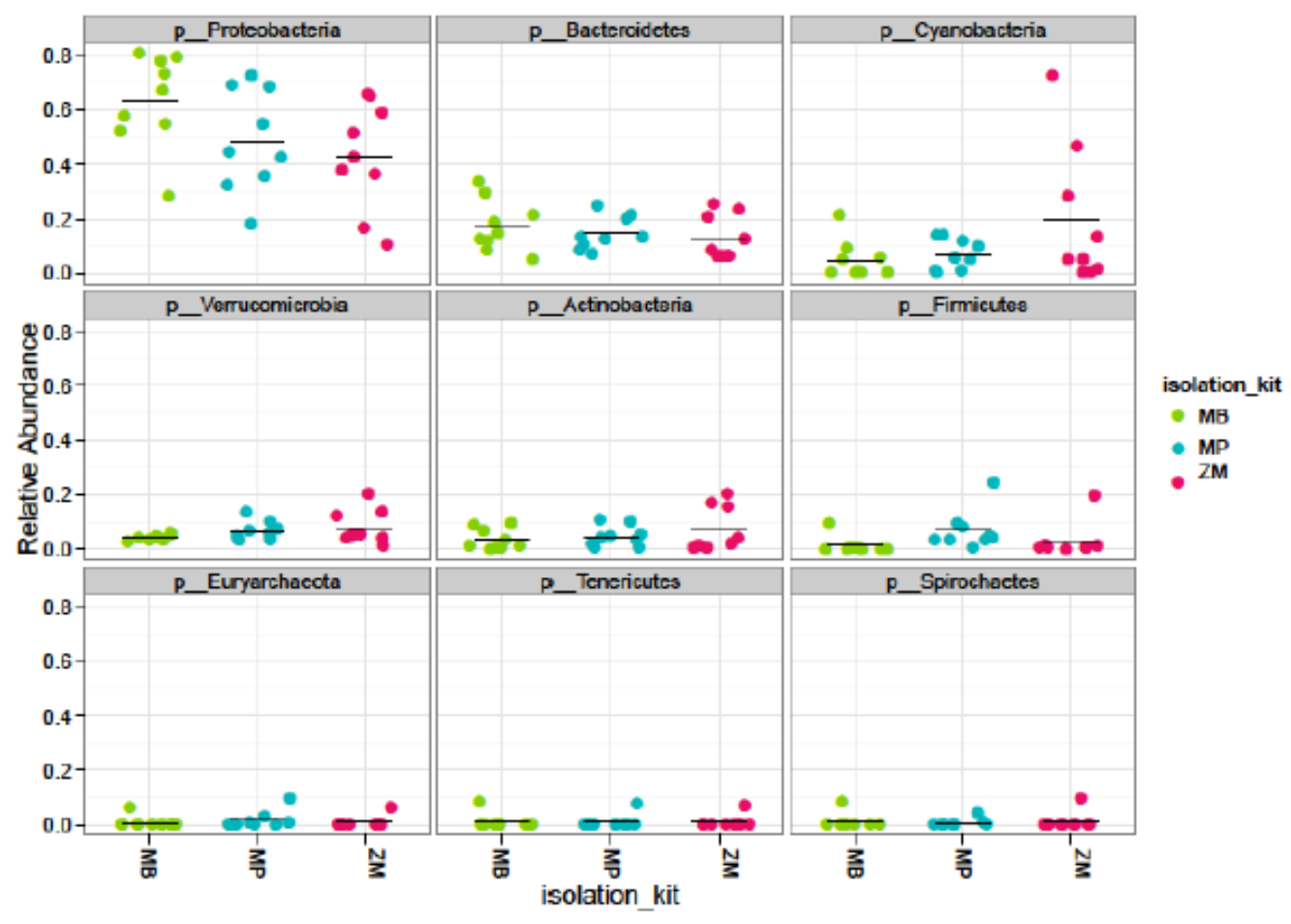

Fig. 4A 


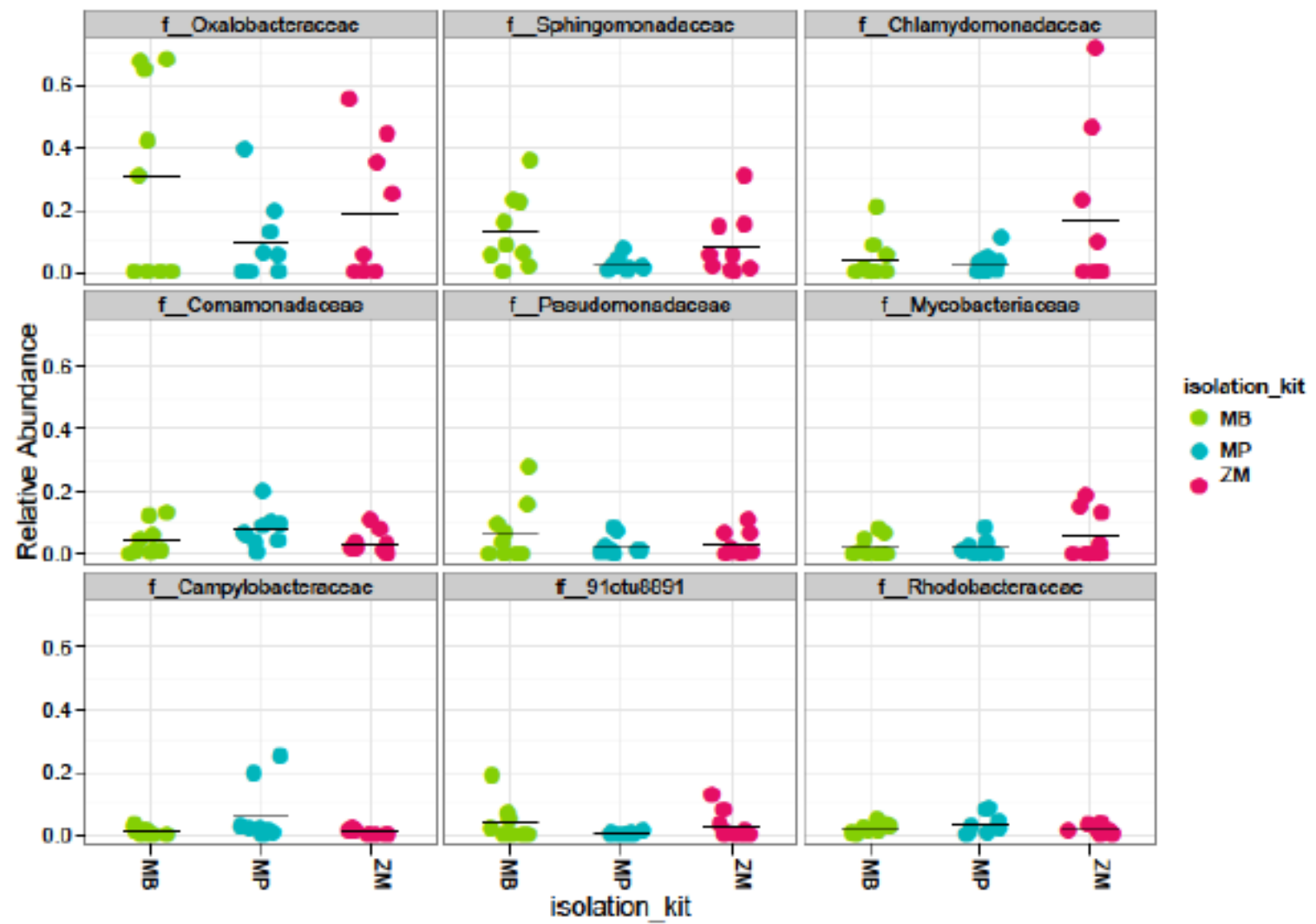

Fig. 4B 


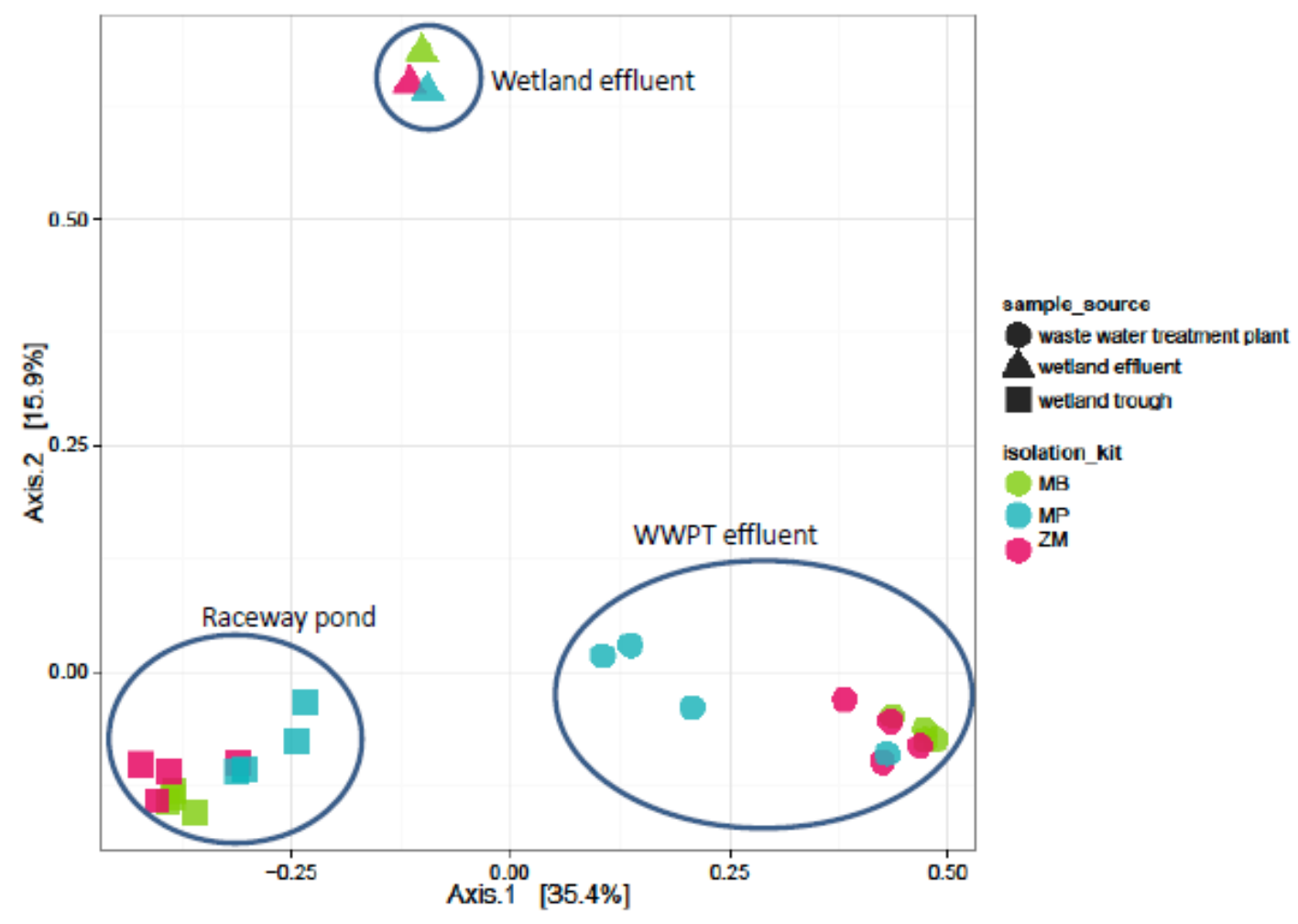

Fig. 5A 


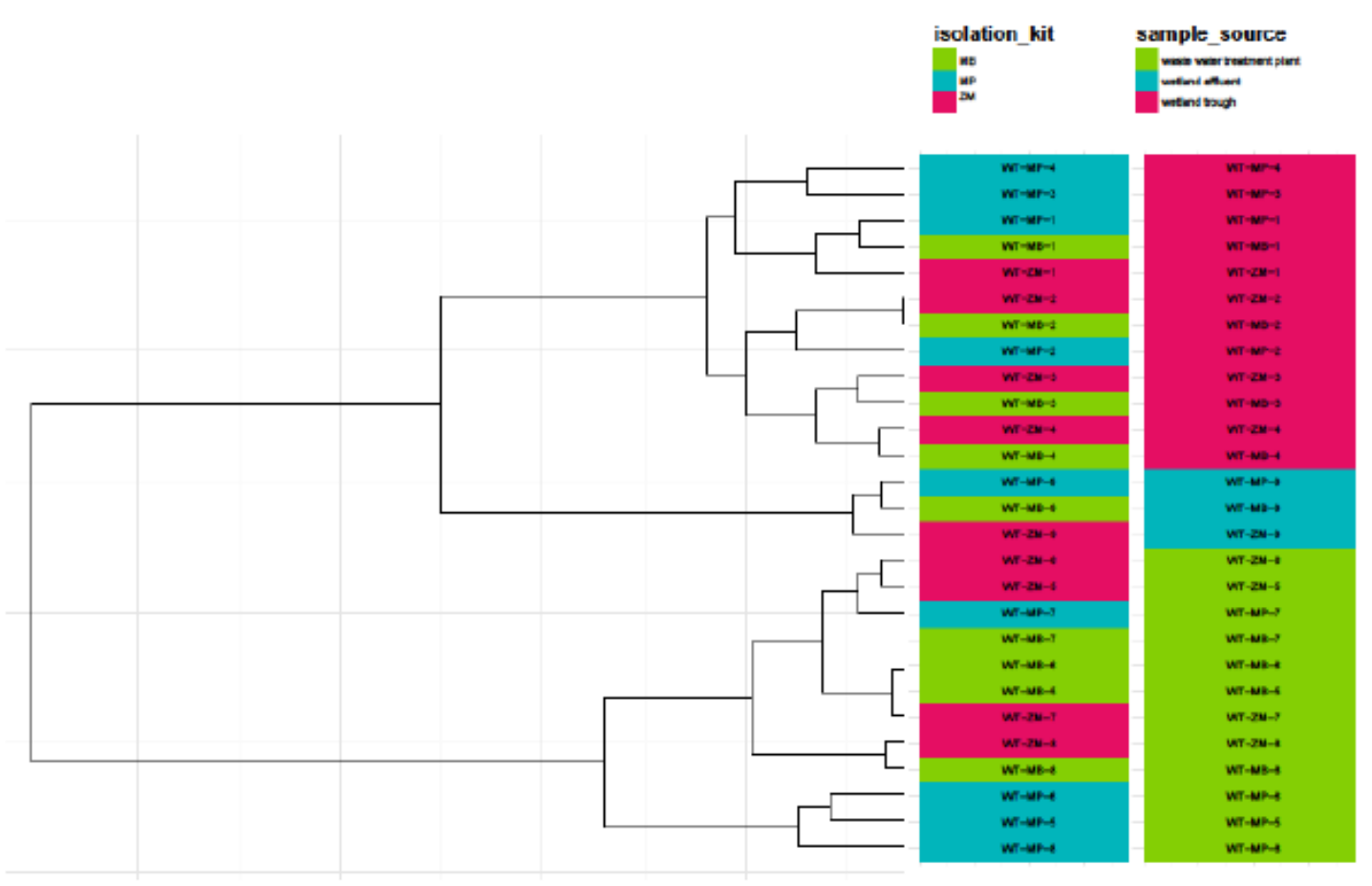

Fig. 5B 


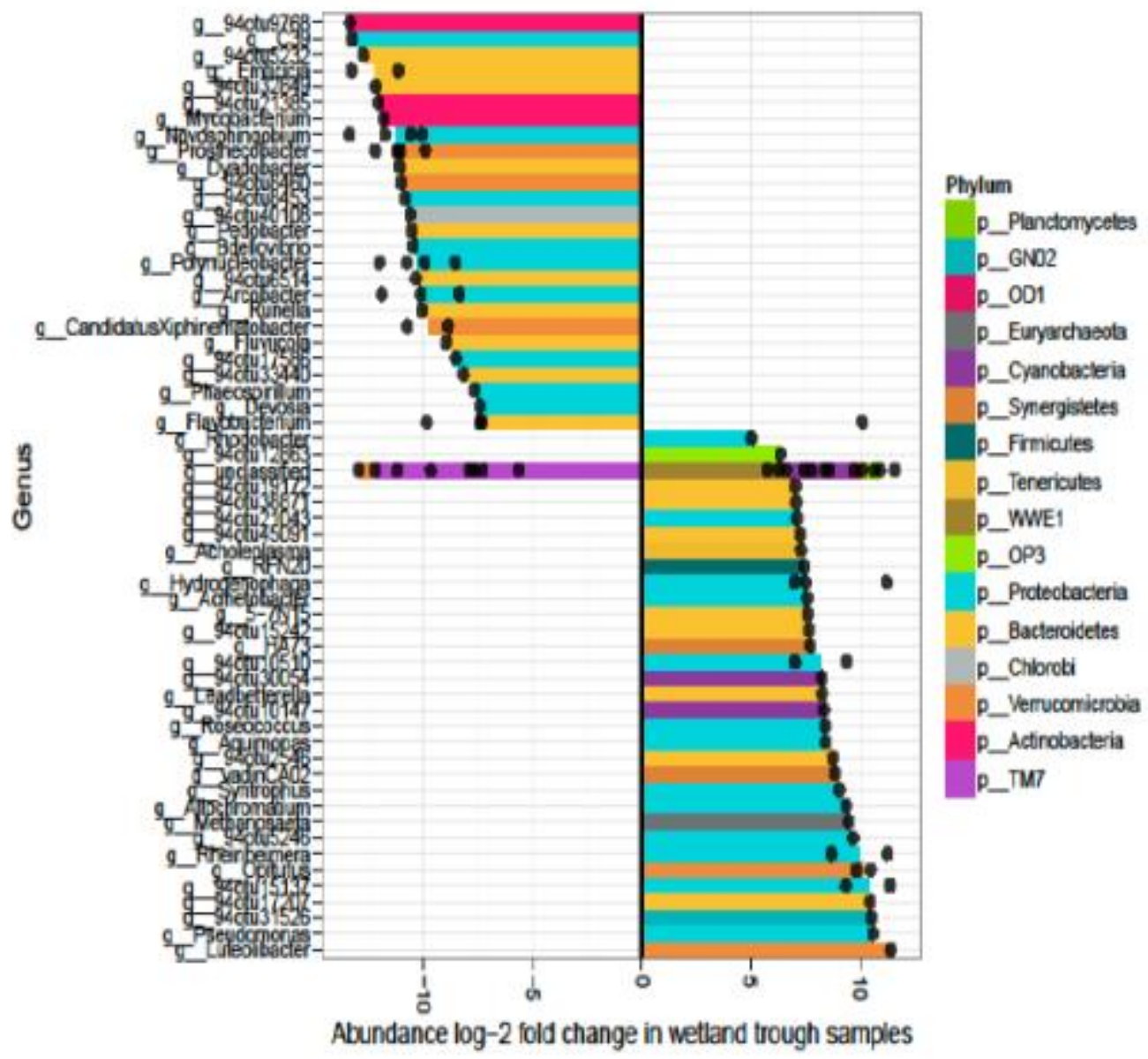

Fig. 6A-Mo Bio 


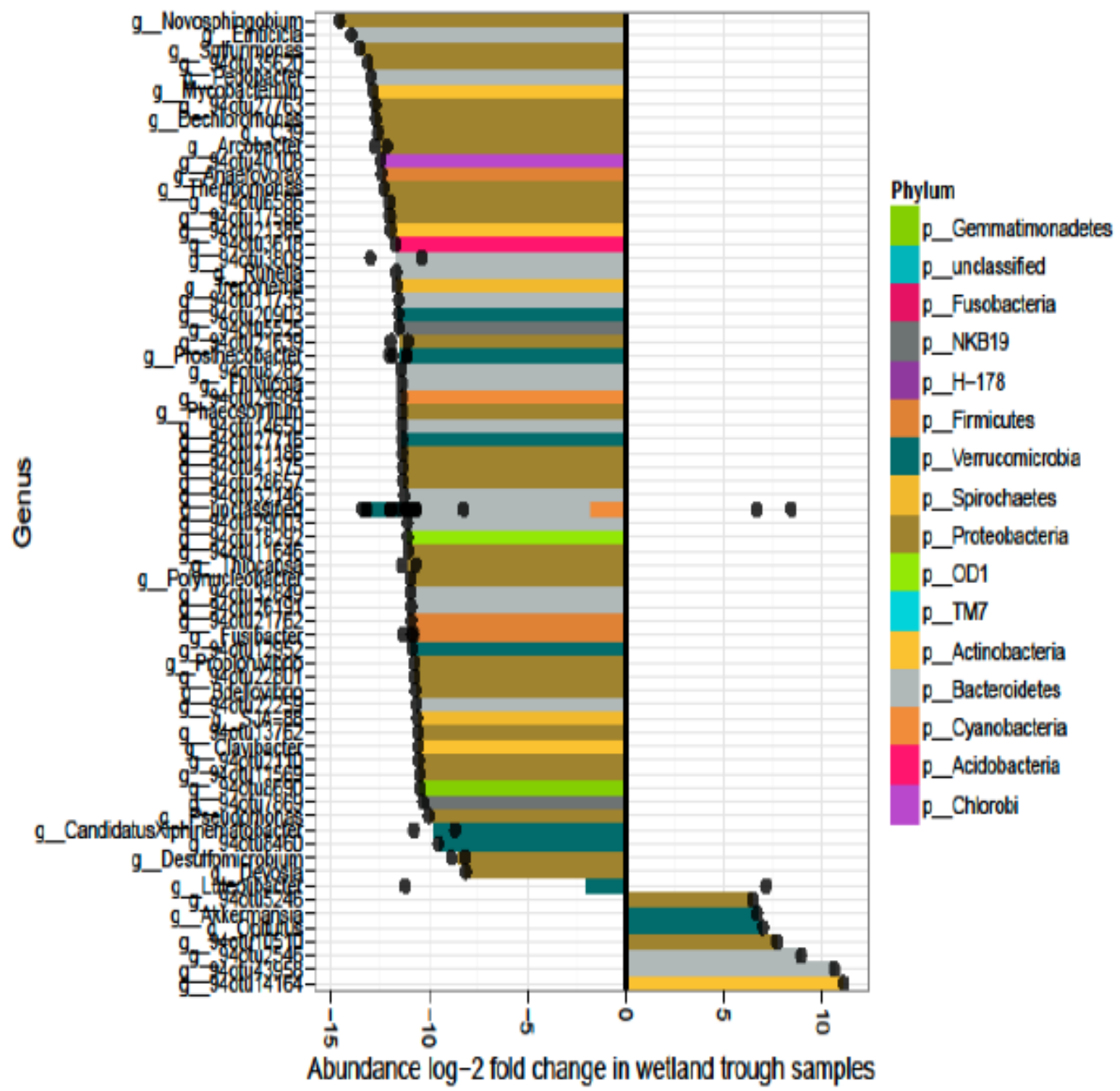

Fig. 6B 


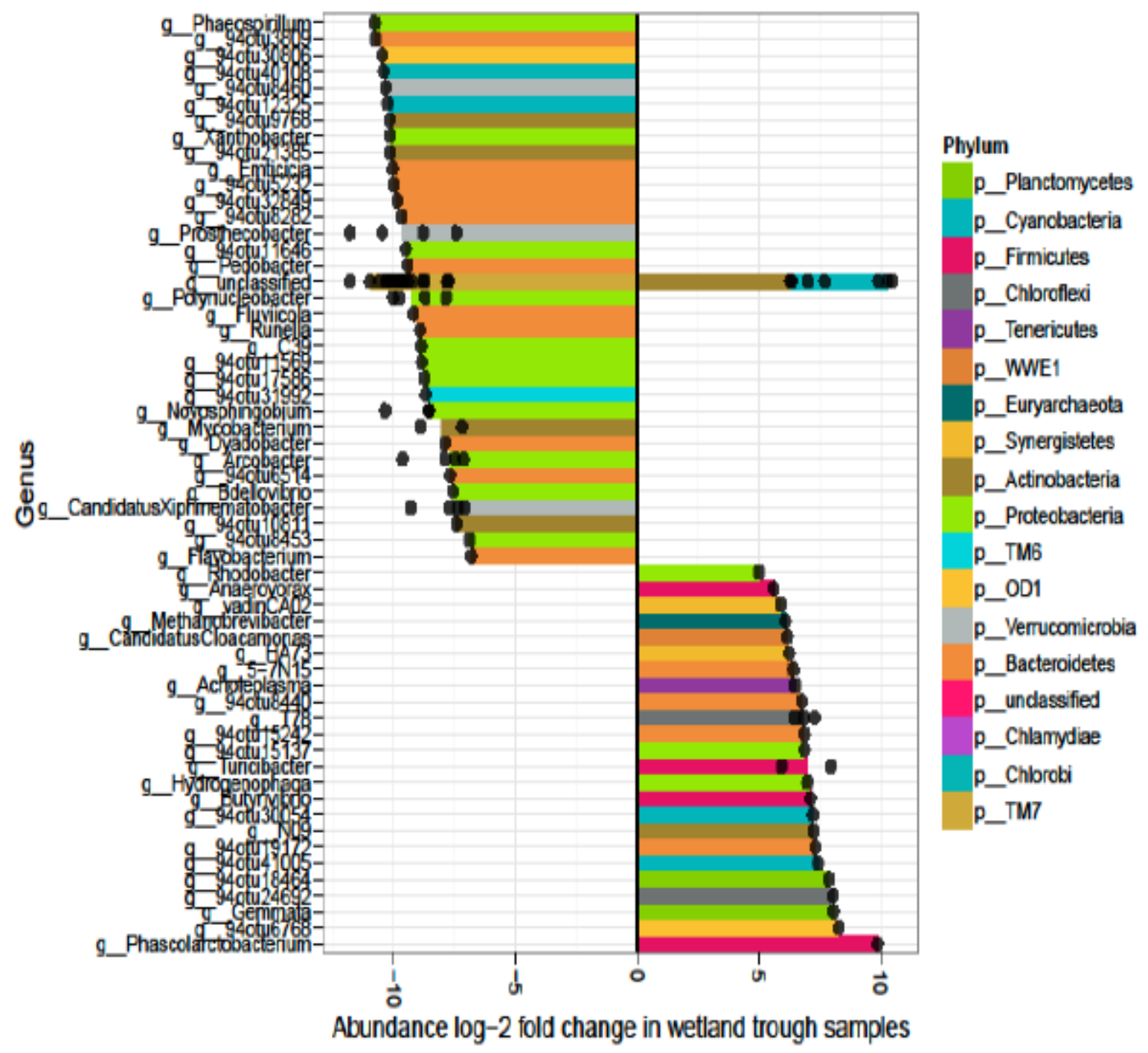

Fig. 6C 


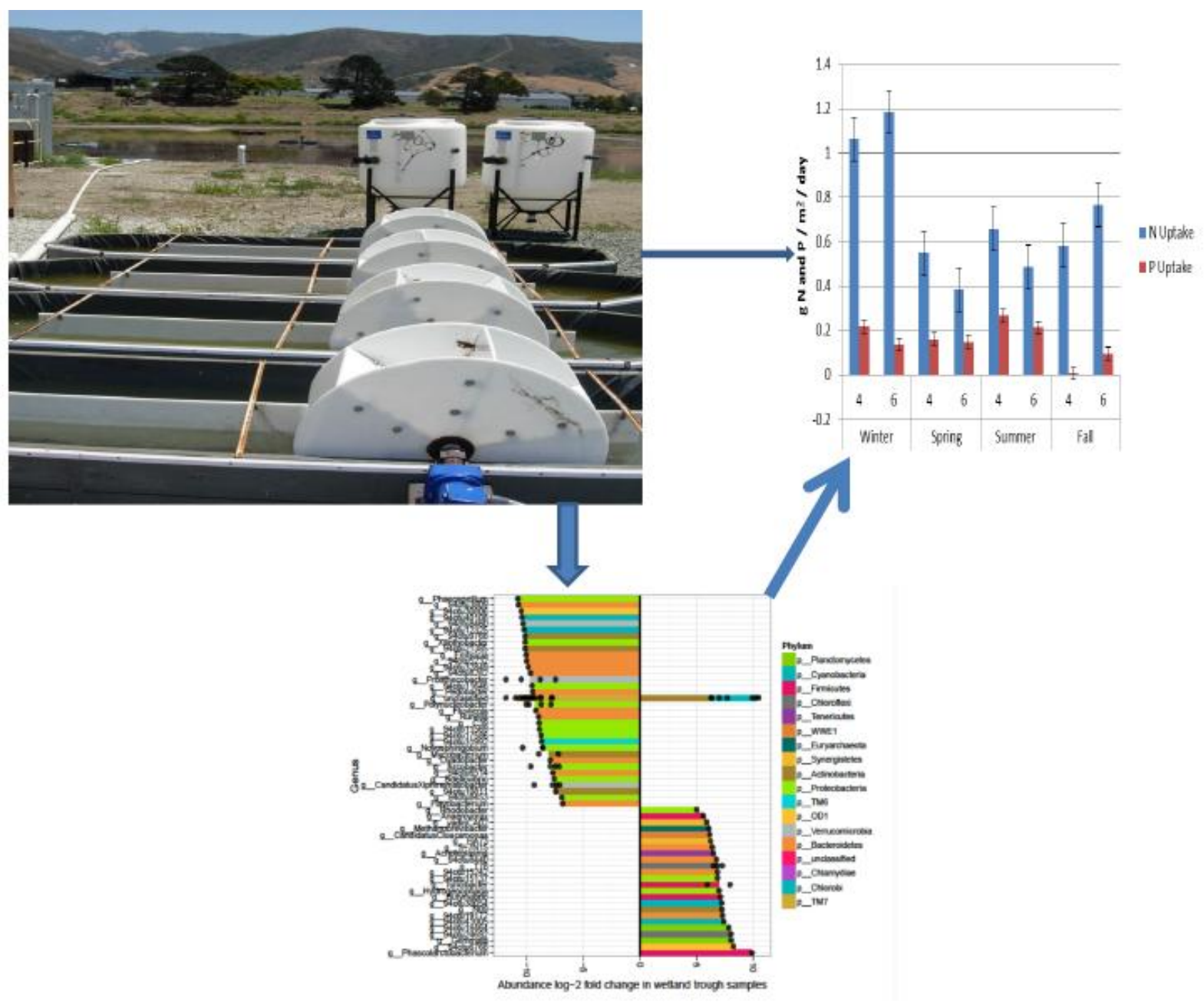

Graphical abstract 